\title{
Platinum-Catalyzed Direct Amination of Allylic Alcohols
}

\author{
Takashi Ohshima ${ }^{1}$ and Kazushi Mashima ${ }^{2}$ \\ ${ }^{1}$ Graduate School of Pharmaceutical Sciences, Kyushu University \\ Maidashi Higashi-ku, Fukuoka 812-8582, Japan \\ ${ }^{2}$ Department of Chemistry, Graduate School of Engineering Science, Osaka University \\ Toyonaka, Osaka 560-8531, Japan
}

(Received July 18, 2012; E-mail: ohshima@phar.kyushu-u.ac.jp; mashima@chem.es.osaka-u.ac.jp)

\begin{abstract}
Transition metal-catalyzed amination of allylic compounds via a $\pi$-allylmetal intermediate is a powerful and useful method for synthesizing allylamines. Direct catalytic substitution of allylic alcohols with amines, which forms water as the sole coproduct, has recently attracted attention in terms of its environmental and economical advantages. Here, we describe the development of a direct catalytic amination of both aryland alkyl-substituted allylic alcohols with various amines including the smallest nitrogen nucleophile ammonia using $\mathrm{Pt}-\mathrm{Xantphos}$ and $\mathrm{Pt}-\mathrm{DPEphos}$ catalyst systems, which allow the selective synthesis of various monoallylamines including the biologically active compounds naftifine and flunarizine, in good to high yield without requiring any activator.
\end{abstract}

\section{Introduction}

Allylamines are ubiquitous components of biologically active compounds, ${ }^{1}$ such as the antifungal drug naftifine ${ }^{2 a, b}$ and the calcium channel blocker flunarizine, ${ }^{2 c, d}$ and are versatile substrates used for different types of reactions, including asymmetric isomerization ${ }^{3}$ and ring-closing metathesis. ${ }^{4}$ Thus, as a reliable synthetic methodology to obtain a wide variety of allylamines and their derivatives, nucleophilic substitution reactions of allylic substrates with amines have been widely utilized. ${ }^{5}$ These standard synthetic protocols usually require activated allylic compounds $\mathbf{2}$, such as allylic halides, carboxylates, carbonates, and phosphates, which are usually derived from the corresponding allylic alcohol $\mathbf{1}$, prior to metal catalyzed transformation; however, the use of the activated substrates 2 lead to the formation of more than stoichiometric amounts of unwanted salt waste both in the preactivation and amination steps (Scheme 1, $\mathbf{1} \rightarrow \mathbf{2} \rightarrow \mathbf{4}$ ). Thus, direct catalytic amination of underivatized allylic alcohols $\mathbf{1}$, which forms water as the sole coproduct, is highly desirable $(\mathbf{1} \rightarrow \mathbf{4}){ }^{6}$ Such direct reactions, however, are rarely explored because of the poor leaving ability of the hydroxyl group. Nonetheless, for activating the hydroxyl group, two powerful and reliable methods are subjected; (1) Lewis or Brønsted acid-catalyzed direct amination via a carbocation intermediate $(\mathbf{1} \rightarrow \mathbf{5} \rightarrow \mathbf{4})$ and $(2)$ transition metal-catalyzed direct amination via a $\pi$-allylmetal intermediate $(\mathbf{1} \rightarrow \mathbf{6} \rightarrow \mathbf{4})$. These two methods are complementary approaches to compensate weak point of each method. In general, the former method is efficient for electron-deficient nitrogen nucleophiles such as sulfonylamides, carbamates, simple amides, and anilines with electron-withdrawing groups (electron-rich nitrogen nucleophiles are not good substrates because they deactivate acid catalysts). In association with the former method, various Lewis and Brønsted acid catalyses have been developed. ${ }^{7}$ We also successfully developed $\mathrm{Au}(\mathrm{III})$ salt-catalyzed direct aminations of allylic and benzylic alcohols with highly functionalized amine nucleophiles ${ }^{8 \mathrm{a}}$ and $\mathrm{Al}(\mathrm{OTf})_{3}$-catalyzed direct amination of allylic alcohols, ben- zylic alcohols, and benzhydrols bearing an electron-withdrawing $\mathrm{F}, \mathrm{Br}, \mathrm{I}, \mathrm{NO}_{2}$, or $\mathrm{CN}$ substituent. ${ }^{8 \mathrm{~b}}$ The latter method is available for electron-rich amines such as alkylamines and anilines with electron-donating groups (electron-deficient nitrogen nucleophiles are not good substrates because of their low nucleophilicity). We recently succeeded in the development of direct catalytic amination of both aryl- and alkyl-substituted allylic alcohols with various amines including ammonia using Pt-Xantphos and Pt-DPEphos catalyst systems, which allow for the selective synthesis of various monoallylamines. ${ }^{9}$ In this account, we thus review the transition metal-catalyzed direct amination of allylic alcohols.

Scheme 1. Preparation of allylamine $\mathbf{4}$ from allylic alcohol $\mathbf{1}$.

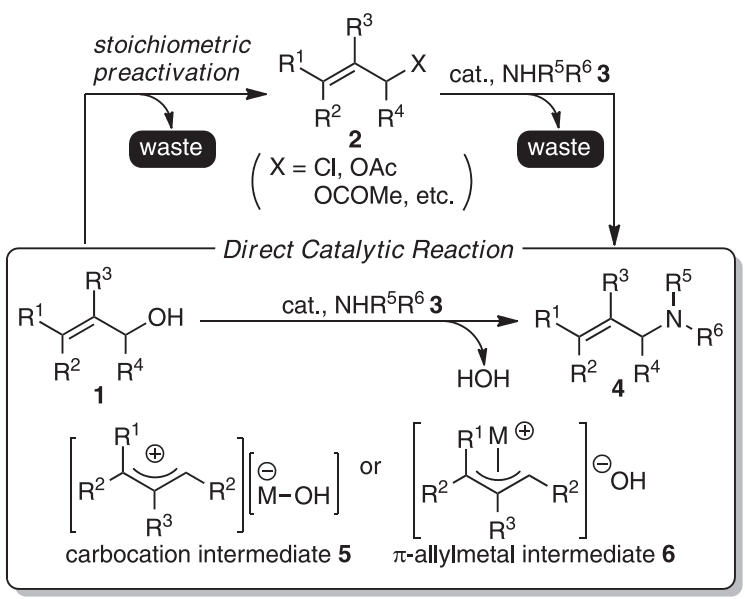

\section{Transition Metal-Catalyzed Direct Amination of Allylic Alcohols (Background)}

Since the pioneering work of $\pi$-allylpalladium chemistry by Tsuji and Trost, various efficient catalyst systems have been developed and are widely applied to the syntheses of natural and unnatural compounds. ${ }^{5}$ A mechanism of transition metalcatalyzed substitution reaction of activated allylic alcohol 
derivatives $\mathbf{2}$ with nitrogen nucleophiles $\mathbf{3}$ is well established to proceed through, the first oxidative addition of allylic substrates to a low-valence metal center, forming $\pi$-allylmetal intermediates $\mathbf{6}$, followed by nucleophilic addition of amines gives allylamines due to the new carbon-nitrogen bond formation with high regio-, stereo-, and enantioselectivity. ${ }^{5}$ In terms of atom-economy ${ }^{10}$ and environmental impact, the development of a direct catalytic substitution of underivatized allylic alcohols 1 with amines 3, which produces the desired allylamines $\mathbf{4}$ together with water as the sole coproduct $(\mathbf{1} \rightarrow \mathbf{6} \rightarrow \mathbf{4})$, is more straightforward and desirable. ${ }^{6}$ However, for overcoming the poor leaving ability of the hydroxyl group, the previously reported catalytic direct aminations require rather severe reaction conditions and/or the addition of considerable amounts of an activator such as $\mathrm{As}_{2} \mathrm{O}_{3},{ }^{11} \mathrm{~B}_{2} \mathrm{O}_{3},{ }^{12} \mathrm{SnCl}_{2},{ }^{13}$ $\mathrm{PPh}_{3}-\mathrm{DEAD},{ }^{14} \mathrm{Ti}(\mathrm{O}-i-\mathrm{Pr})_{4},{ }^{15} \mathrm{BPh}_{3},{ }^{16} \mathrm{BF}_{3} \cdot \mathrm{Et}_{2} \mathrm{O},{ }^{17} \quad \mathrm{CO}_{2}{ }^{18}$ $\mathrm{BEt}_{3},{ }^{19}$ and $1-\mathrm{AdCO}_{2} \mathrm{H},{ }^{20}$ including an efficient enantioselective variant. ${ }^{21}$ In 2002, Ozawa and Yoshifuji reported that several palladium complexes supported by $\mathrm{sp}^{2}$-hybridized phosphorus ligands catalyzed direct aminations of allylic alcohols 1 without the use of an activator. ${ }^{22}$ This pioneering work led to the development of a highly atom economical synthetic process for allylamines by several research groups of Ikariya, ${ }^{23}$ Shinokubo and Oshima, ${ }^{24}$ le Floch, ${ }^{25}$ and Breit, ${ }^{26}$ although the substrate generality of those reactions remained limited: in particular, the reaction with aliphatic primary amines resulted only in the formation of diallylation products, ${ }^{23,24}$ consistent with the higher nucleophilicity of the monoallylation product compared to that of the starting substrate.

\section{Platinum-Catalyzed Direct Amination of Allylic Alcohols}

\subsection{Development and Optimization of Platinum Catalysis}

A rate-determining step of the above-mentioned $\mathrm{Pd}$-catalyzed substitution reactions of allylic alcohol is the activation of the hydroxyl group to form a $\pi$-allyl complex. Because the $\mathrm{Pt}-\mathrm{O}$ bond is stronger than the $\mathrm{Pd}-\mathrm{O}$ bond, ${ }^{27}$ we anticipated that the platinum complex would be a good candidate for a direct amination catalyst for allylic alcohols. We first examined various phosphine ligands in the reaction of allyl alcohol (1a) and aniline (3a) using $\mathrm{Pt}(\mathrm{cod}) \mathrm{Cl}_{2}$ as a metal source. ${ }^{9 \mathrm{a}}$ The reaction did not proceed in the absence of a phosphine ligand (Table 1, entry 1) and the use of monodentate ligands gave unsatisfactory results (entries 2-4), in sharp contrast to the reports that $\mathrm{Pd}-$ monophosphine ligand complexes have good catalyst activity. ${ }^{23,24}$ Commonly used diphosphine ligands, such as DPPE, DPPP, DPPF, and BINAP also produced low yields (entries 5-10). In contrast, the use of the large bite-angle ligands, ${ }^{28}$ such as DPEphos ${ }^{29}$ and Xantphos ${ }^{30}$ dramatically improved the catalyst activity for this reaction, giving rise to the desired product 4aa in 91\% yield (entry 11 ) and $86 \%$ yield (entry 12), respectively. To the best of our knowledge, this is the first example of a platinum-catalyzed direct amination of allylic alcohols without the use of any activators. ${ }^{15 \mathrm{~d}, 31}$

Table 1 shows that the bite-angle of the chelating ligands bound to the palladium atom is a good indicator for the platinum-catalyzed direct amination activity, in accordance with the reported tendency toward faster nucleophilic attack on $\pi^{-}$ allylpalladium complexes with larger $\mathrm{P}-\mathrm{Pd}-\mathrm{P}$ bite-angles than with smaller bite-angles. ${ }^{28}$ Thus, we examined the ligand effects in more detail under the optimized conditions in DMF (vide infra). ${ }^{9 \mathrm{~b}}$ We tested various large bite-angle diphosphine
Table 1. Ligand effects on Pt-catalyzed direct amination of allyl alcohol (1a).

\begin{tabular}{|c|c|c|c|c|}
\hline $1 a$ & \multicolumn{3}{|c|}{$\begin{array}{cc} & \mathrm{Pt}(\mathrm{cod}) \mathrm{Cl}_{2}(1.0 \mathrm{~mol} \%) \\
& \text { ligand }(\mathrm{x} \mathrm{mol} \mathrm{\% )} \\
& (\mathrm{P} / \mathrm{Pt}=4)^{b} \\
\end{array}$} & 4aa \\
\hline entry & ligand $(\mathrm{x})$ & & bite-angle $(\beta)^{b}$ & yield $(\%)^{c}$ \\
\hline 1 & - & & & 0 \\
\hline 2 & $\mathrm{PPh}_{3}(4.0)$ & & & 11 \\
\hline 3 & $\mathrm{P}(\mathrm{OPh})_{3}(4.0)$ & & & 7 \\
\hline 4 & $\mathrm{P}(2 \text {-furyl })_{3}(4.0)$ & & & 36 \\
\hline 5 & DPPE (2.0) & & $85^{\circ}$ & 0 \\
\hline 6 & $\left(\mathrm{C}_{6} \mathrm{~F}_{5}\right)_{2} \mathrm{PCH}_{2} \mathrm{CH}_{2} \mathrm{P}\left(\mathrm{C}_{6}\right.$ & $2(2.0)$ & & 1 \\
\hline 7 & $\operatorname{DPPP}(2.0)$ & & $90^{\circ}$ & 0 \\
\hline 8 & $\mathrm{Ph}_{2} \mathrm{P}\left(\mathrm{CH}_{2}\right)_{5} \mathrm{PPh}_{2}(2.0)$ & & & 9 \\
\hline 9 & DPPF (2.0) & & $90^{\circ}$ & 29 \\
\hline 10 & BINAP (2.0) & & $93^{\circ}$ & 4 \\
\hline 11 & DPEphos (2.0) & & $104^{\circ}$ & 91 \\
\hline 12 & Xantphos (2.0) & & $108^{\circ}$ & 86 \\
\hline
\end{tabular}

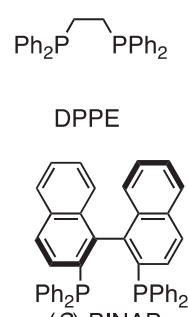

(S)-BINAP
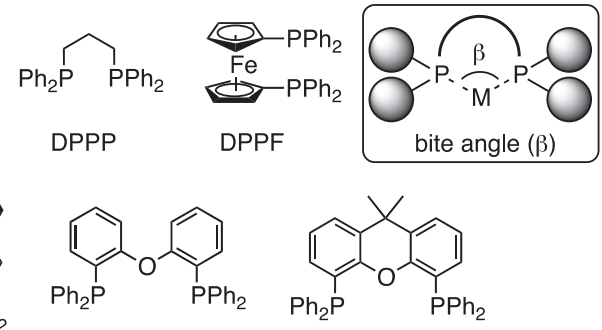

DPEphos

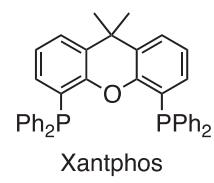

ligands, and results are shown in Table 2. Because of the lack of information about the bite-angles of $\operatorname{Pt}\left(\eta^{3}\right.$-allyl)(diphosphine) complexes, the bite-angles $(\beta)$ shown in Table 2 were obtained by geometry optimization using the $\mathrm{B}^{2} \mathrm{LYP}^{32}$ hybrid density functional theory (LANL2DZ for Pt and 6-31G(d,p) for others). Although 1,2-bis(diphenylphosphino)benzene $\left(\beta=87^{\circ}\right)$, DPPP $\left(\beta=96^{\circ}\right)$, BINAP $\left(\beta=97^{\circ}\right)$, and SEGPHOS $\left(\beta=98^{\circ}\right)$ ligands, whose bite angles are smaller than $100^{\circ}$, did not promote the reaction (entries 1-4), larger bite-angle ligands such as 6-DPPon, ${ }^{26}$ which in situ dimerizes in aprotic solvent through hydrogen bonding and acts as a bidentate ligand $\left(\beta=104^{\circ}\right),{ }^{33}$ and Trost ligand $\left(\beta=107^{\circ}\right),{ }^{34}$ had moderate reactivity to afford allylamine $\mathbf{4 b a}$ in $40 \%$ (entry 5 ) and $19 \%$ (entry 6) yields, respectively. The use of DPEphos $\left(\beta=107^{\circ}\right)^{29}$ and Xantphos $\left(\beta=108^{\circ}\right)^{30}$ obviously improved catalyst activity with the best performance of Xantphos (entry 8, 80\% yield). On the other hand, the use of the structurally related POP ligand $\left(\beta=108^{\circ}\right)^{35}$ and $t-\mathrm{Bu}-\mathrm{Xantphos}\left(\beta=112^{\circ}\right)^{36}$ afforded no product (entries 9 and 11) despite their large bite-angle. These findings clearly indicated that, in addition to a large bite-angle, an efficient chelating ligand should be composed of fully arylor alkenyl ${ }^{37}$-substituted phosphines. Moreover, the very low reactivity when using the Floriani ligand $\left(\beta=111^{\circ}\right)^{38}$ (entry 10), which is a methylene-linked variant of DPEphos, strongly suggests the importance of the linker oxygen in DPEphos and Xantphos.

We next screened for the best platinum source together 
Table 2. Effects of diphosphine ligands on Pt-catalyzed direct amination.

\begin{tabular}{|c|c|c|c|c|}
\hline \multirow[b]{2}{*}{$1 \mathrm{~b}$} & \multicolumn{3}{|c|}{$\begin{array}{c}\mathrm{Pt}(\operatorname{cod}) \mathrm{Cl}_{2}(1.0 \mathrm{~mol} \% \\
\text { ligand }(2.0 \mathrm{~mol} \%) \\
(\mathrm{P} / \mathrm{Pt}=4)^{b}\end{array}$} & \multirow[b]{2}{*}{$4 \mathrm{ba}$} \\
\hline & & $\begin{array}{c}\text { (1.5 equiv) } \\
\text { 3a }\end{array}$ & $\begin{array}{c}\text { DMF } \\
50{ }^{\circ} \mathrm{C}, 18 \mathrm{~h}\end{array}$ & \\
\hline & entry & ligand & bite angle $(\beta)^{c}$ & yield of $\mathbf{4} \mathbf{b a}^{d}$ \\
\hline & 1 & $\mathrm{C}_{6} \mathrm{H}_{4}-1,2-\left(\mathrm{PPh}_{2}\right)_{2}$ & $87^{\circ}$ & $\mathrm{nd}^{e}$ \\
\hline & 2 & DPPP & $96^{\circ}$ & $\mathrm{nd}^{e}$ \\
\hline & 3 & BINAP & $97^{\circ}$ & $\mathrm{nd}^{e}$ \\
\hline & 4 & SEGPHOS & $98^{\circ}$ & $\mathrm{nd}^{\mathrm{e}}$ \\
\hline & $5^{f}$ & 6-DPPon & $104^{\circ}$ & $40 \%$ \\
\hline & 6 & Trost ligand & $107^{\circ}$ & $19 \%$ \\
\hline & 7 & DPEphos & $107^{\circ}$ & $71 \%$ \\
\hline & 8 & Xantphos & $108^{\circ}$ & $80 \%$ \\
\hline & 9 & POP ligand & $108^{\circ}$ & $\mathrm{nd}^{e}$ \\
\hline & 10 & Floriani ligand & $111^{\circ}$ & $8 \%$ \\
\hline & 11 & $t$-Bu-Xantphos & $112^{\circ}$ & $\mathrm{nd}^{e}$ \\
\hline
\end{tabular}

${ }^{a} 2.0 \mathrm{mmol}$ scale, $0.4 \mathrm{~mL}$ of DMF was used. ${ }^{b}$ Phosphine to platinum ratio (P/Pt). ${ }^{c}$ Bite-angle of $\left[\mathrm{Pt}\left(\eta^{3} \text {-allyl)(diphosphine }\right)\right]^{+}$ optimized with B3LYP function. ${ }^{d}$ Determined by GC analysis. ${ }^{e}$ Not detected in the reaction mixture. ${ }^{f} 4 \mathrm{~mol} \%$ of ligand was used to keep P/Pt to 4.

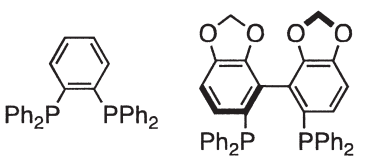

(S)-SEGPHOS

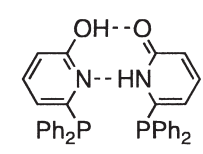

(6-DPPon $)_{2}$

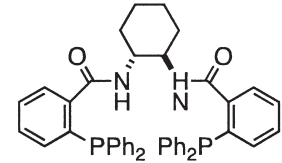

Trost ligand<smiles>Pc1ccccc1Cc1ccccc1P</smiles>

Floriani ligand

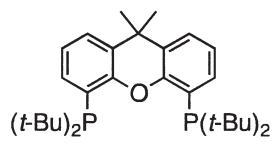

$t$-Bu-Xantphos<smiles>Pc1ccccc1</smiles>

POP ligand with the potential use of palladium and nickel complexes using DPEphos as a ligand. Under dioxane reflux conditions, Pt(II) complex $\mathrm{Pt}($ cod $) \mathrm{Cl}_{2}$ and $\mathrm{Pt}(0)$ complex $\mathrm{Pt}\left(\mathrm{PPh}_{3}\right)_{4}$ gave the product in high yield, though other $\mathrm{Pt}(\mathrm{II})$ complexes such as $\mathrm{Pt}(\operatorname{cod})(\mathrm{OTf})_{2}$ gave low to moderate yield. ${ }^{9 \mathrm{a}}$ On the other hand, under the optimized conditions in DMF as shown in Table 2, $\mathrm{Pt}(0)$ complex had only moderate catalytic activity. ${ }^{9 b}$ In addition, as part of our program studying the use of metal clusters as cooperative catalysts, we were interested in the use of tetraplatinum complex $\mathrm{Pt}_{4}\left(\mu-\mathrm{OCOCH}_{3}\right)_{8}{ }^{39}$ and its derivatives ${ }^{40,41}$ as the catalyst for direct amination. These phosphine-free tetraplatinum complexes also promoted the reaction; however, those catalytic activities were much lower than that of PtDPEphos complex. ${ }^{42}$ The combination of palladium with DPEphos gave only a low yield ${ }^{43}$ and nickel complexes did not promote the reaction at all.

Under the initial optimized conditions in dioxane as shown in Table 1, the platinum catalysis proceeded with high monoallylation selectivity of both aromatic (up to >88:1) and aliphatic (up to 30:1) primary amines. ${ }^{9 a}$ To further improve catalyst activity, we examined solvent effects at $110{ }^{\circ} \mathrm{C}$ or the solvent reflux temperature (Table 3 , entries $1-7$ ). ${ }^{9 \mathrm{~b}}$ To clarify the solvent effects, reactions were stopped after $3 \mathrm{~h}$ and the yield of allylamine $\mathbf{4 b a}$ was determined by gas chromatographic analysis. Among the solvents examined, dioxane (entry 3, 72\%), which was the initial best solvent, ${ }^{9 a}$ and DMF (entry 5, 79\%) gave good results, in sharp contrast to the unsatisfactory result obtained with the closely related solvent DMA (entry 4, 22\%). Interestingly, a marked difference between dioxane (entry 8 , $<1 \%$ ) and DMF (entry 9, 89\%) was observed at a lower temperature $\left(50{ }^{\circ} \mathrm{C}\right)$ with a prolonged reaction time $(23 \mathrm{~h})$. Using DMF as the solvent, the direct amination of $\mathbf{1 b}$ proceeded even at room temperature, although the yield was moderate even after $78 \mathrm{~h}$ (entry 10, 52\%). Further, platinum catalysis proceeded under solvent-free conditions with reasonably good reactivity (entry $7,57 \%$ ), providing great possibility for the development of a more efficient and environmentally friendly catalytic synthetic process of allylamines.

Table 3. Effects of solvents and reaction temperature on Ptcatalyzed direct amination with arylamine $\mathbf{3 a}{ }^{a}$

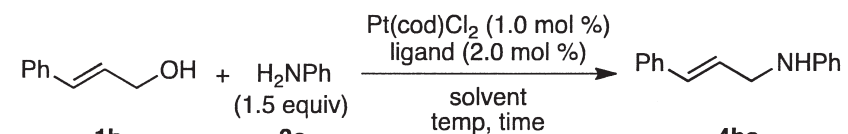

$1 \mathrm{~b}$

$3 a$ temp, time

4ba

\begin{tabular}{cllcc}
\hline entry & solvent & temp & time $(\mathrm{h})$ & yield of $\mathbf{4} \mathbf{b a}^{b}$ \\
\hline 1 & toluene & $110{ }^{\circ} \mathrm{C}$ & 3 & $63 \%$ \\
2 & 1,2 -dimethoxyethane & $\operatorname{reflux}\left(82{ }^{\circ} \mathrm{C}\right)^{c}$ & 3 & $38 \%$ \\
3 & dioxane & $\operatorname{reflux}\left(101{ }^{\circ} \mathrm{C}\right)^{c}$ & 3 & $72 \%$ \\
4 & DMA & $110{ }^{\circ} \mathrm{C}$ & 3 & $22 \%$ \\
5 & DMF & $110{ }^{\circ} \mathrm{C}$ & 3 & $79 \%$ \\
6 & DMSO & $110{ }^{\circ} \mathrm{C}$ & 3 & $63 \%$ \\
7 & $-{ }^{d}$ & $110{ }^{\circ} \mathrm{C}$ & 3 & $57 \%$ \\
8 & dioxane & $50{ }^{\circ} \mathrm{C}$ & 23 & $<1 \%$ \\
9 & DMF & $50{ }^{\circ} \mathrm{C}$ & 23 & $89 \%$ \\
10 & DMF & $\mathrm{rt}$ & 78 & $52 \%$ \\
\hline
\end{tabular}

${ }^{a} 2.0 \mathrm{mmol}$ scale, $0.4 \mathrm{~mL}$ of solvent was used. ${ }^{b}$ Determined by GC analysis.

${ }^{c}$ Boiling point of pure solvent. ${ }^{d}$ Solvent-free conditions.

Organic synthesis assisted by microwave heating has grown rapidly since the pioneering work of Gedye in $1986 .{ }^{44}$ In many organic transformations, microwave heating dramatically decreases the reaction times and increases the product yields in comparison with conventional heating methods. Accordingly, we examined our $\mathrm{Pt}$-catalyst reaction under microwave irradiation conditions (Scheme 2). ${ }^{9 b}$ To our surprise, upon using a CEM Discover single-mode microwave reactor, the reaction at $50{ }^{\circ} \mathrm{C}$ for $1 \mathrm{~h}$ was sufficient for full conversion compared with the $4 \mathrm{~h}$ conventional heating for completion. ${ }^{45}$

Finally, optimization of the best ratio between the chelating ligand, Xantphos, and platinum was performed using para-methoxyaniline (3b) under microwave irradiation condi-

Scheme 2. Effects of microwave irradiation on Pt-catalyzed direct amination.

\begin{tabular}{|c|c|c|c|c|c|}
\hline \multirow{2}{*}{\multicolumn{2}{|c|}{$\mathbf{1 b}+\begin{array}{c}\mathbf{3 a} \\
(1.5 \text { equiv })\end{array}$}} & $\begin{array}{c}\mathrm{Pt}(\operatorname{cod}) \mathrm{Cl}_{2}(1.0 \mathrm{~mol} \%) \\
\text { Xantphos }(2.0 \mathrm{~mol} \%)\end{array}$ & & & \\
\hline & & $\begin{array}{c}\text { DMF, } 50^{\circ} \mathrm{C}, 4 \mathrm{~h} \\
\text { conventional } \\
\text { heating }\end{array}$ & 4ba (88\%) & & 7 ba $(5 \%)$ \\
\hline \multirow{2}{*}{$1 b+$} & \multirow{2}{*}{$\begin{array}{c}3 \mathbf{a} \\
\text { (1.5 equiv) }\end{array}$} & $\begin{array}{l}\mathrm{Pt}(\operatorname{cod}) \mathrm{Cl}_{2}(1.0 \mathrm{~mol} \%) \\
\text { Xantphos }(2.0 \mathrm{~mol} \%) \\
\end{array}$ & \multirow{2}{*}{ 4ba (85\%) } & \multirow{2}{*}{+} & \multirow{2}{*}{7 ba (6\%) } \\
\hline & & $\begin{array}{c}\mathrm{DMF}, 50^{\circ} \mathrm{C}, 1 \mathrm{~h} \\
\text { microwave } \\
\text { heating }\end{array}$ & & & \\
\hline
\end{tabular}


tions, and results are shown in Table $4 .{ }^{9 b}$ The presence of the extra ligand stopped the reaction (entry 1), and optimal results were obtained with Xantphos to platinum ratio of 1:1 (entry 4), indicating that the active catalyst species would be a coordinately unsaturated Pt-xantphos 1:1 complex. Under the optimal reaction conditions, the use of only $0.5 \mathrm{~mol} \%$ of the catalyst completed the reaction within $1 \mathrm{~h}$ to give the best yield of 4bb (entry 5), and a turnover number of 570 was achieved upon reducing the catalyst loading to $0.1 \mathrm{~mol} \%$ (entry 6).

Table 4. Effects of ligand to platinum ratio on $\mathrm{Pt}$-catalyzed direct amination with arylamine $\mathbf{3 b}{ }^{a}$

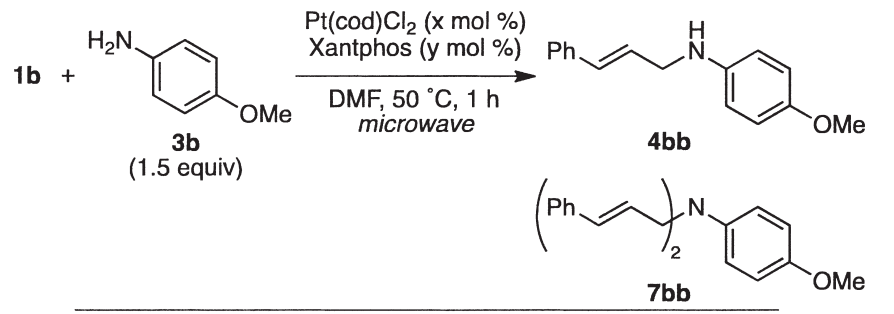

\begin{tabular}{cccccc}
\hline entry & $\begin{array}{c}\mathrm{Pt}(\mathrm{cod}) \mathrm{Cl}_{2} \\
\text { (x mol \%) }\end{array}$ & $\begin{array}{c}\text { Xantphos } \\
(\mathrm{y} \mathrm{mol} \mathrm{\% )})\end{array}$ & $\begin{array}{c}\text { yield of } \\
\mathbf{4} \mathbf{b b}^{b}\end{array}$ & $\begin{array}{c}\text { yield of } \\
\mathbf{7} \mathbf{b b}^{b}\end{array}$ & $\mathrm{TON}^{c}$ \\
\hline 1 & 1.0 & 3.0 & $\mathrm{nd}^{d}$ & $\mathrm{nd}^{d}$ & - \\
2 & 1.0 & 2.0 & $76 \%$ & $5 \%$ & 86 \\
3 & 1.0 & 1.5 & $80 \%$ & $8 \%$ & 96 \\
4 & 1.0 & 1.0 & $84 \%$ & $8 \%$ & 100 \\
5 & 0.5 & 0.5 & $85 \%$ & $7.5 \%$ & 200 \\
$6^{e}$ & 0.1 & 0.1 & $57 \%$ & $<1 \%$ & 570 \\
\hline
\end{tabular}

${ }^{a} 2.0 \mathrm{mmol}$ scale, $0.4 \mathrm{~mL}$ of DMF was used. ${ }^{b}$ Isolated yield. ${ }^{c}$ Turnover number of the platinum catalyst. ${ }^{d}$ Not detected in the reaction mixture.

${ }^{e} 4.0 \mathrm{mmol}$ scale, $0.8 \mathrm{~mL}$ of DMF was used.

\subsection{Direct Amination with Arylamines}

With the optimized conditions $\left(0.5 \mathrm{~mol} \%\right.$ of $\mathrm{Pt}(\mathrm{cod}) \mathrm{Cl}_{2}$, $0.5 \mathrm{~mol} \%$ of Xantphos, microwave irradiation, DMF, $50{ }^{\circ} \mathrm{C}$, $1 \mathrm{~h}$ ) in hand, the scope and limitations of different arylamines 3 were next investigated (Table 5). ${ }^{9 b}$ The reactions of aniline (3a) and various para-substituted anilines $\mathbf{3 c}-\mathbf{h}$ with electronwithdrawing groups were efficiently promoted to provide the desired monoallylation product $\mathbf{4}$ in high yield and high monoallylation selectivity (entries 1-7). The reaction of para-iodoaniline (3f) was the only ineffective case with $3 \%$ of the product $\mathbf{4 b f}$ and recovery of the unreacted $\mathbf{3 f}$, probably due to the oxidative addition of $\mathbf{3 f}$ onto the in situ generated $\mathrm{Pt}(0)$ complex (entry 5). The sterically more congested ortho-chloroaniline (3i) completely prevented the undesired diallylation reaction and predominantly afforded the monoallylation product $4 \mathbf{b i}$ (entry 8, 96\%). Secondary amine $\mathbf{3 j}$ was also a good substrate for this transformation (entry 9, 96\%).

Direct amination of alkyl-substituted allylic alcohols remained an unsolved target. Because our catalytic system using microwave irradiation in DMF greatly improved the catalyst activity and lowered the reaction temperature to $50{ }^{\circ} \mathrm{C}$, we performed direct amination of ally alcohol (1a) and various aryl- and alkyl-substituted allylic alcohols $\mathbf{1} \mathbf{b}-\mathbf{h}$ with aniline (3a) $\left(\right.$ Table 6). ${ }^{9 \mathrm{~b}}$ The reaction of $\mathbf{1 a}$ (entry 1) proceeded smoothly in a manner similar to $\gamma$-phenyl-substituted allylic alcohol $\mathbf{1 b}$ (entry 2). Despite the moderate yield of $\gamma$-methylsubstituted 1c under the previous reaction conditions (43\% yield, dioxane, reflux, $18 \mathrm{~h}$ ), the optimized conditions in DMF allowed for the full conversion of $\mathbf{1} \mathbf{c}$ to the allylated products
Table 5. Pt-catalyzed direct amination with various arylamines 3 . $^{a}$

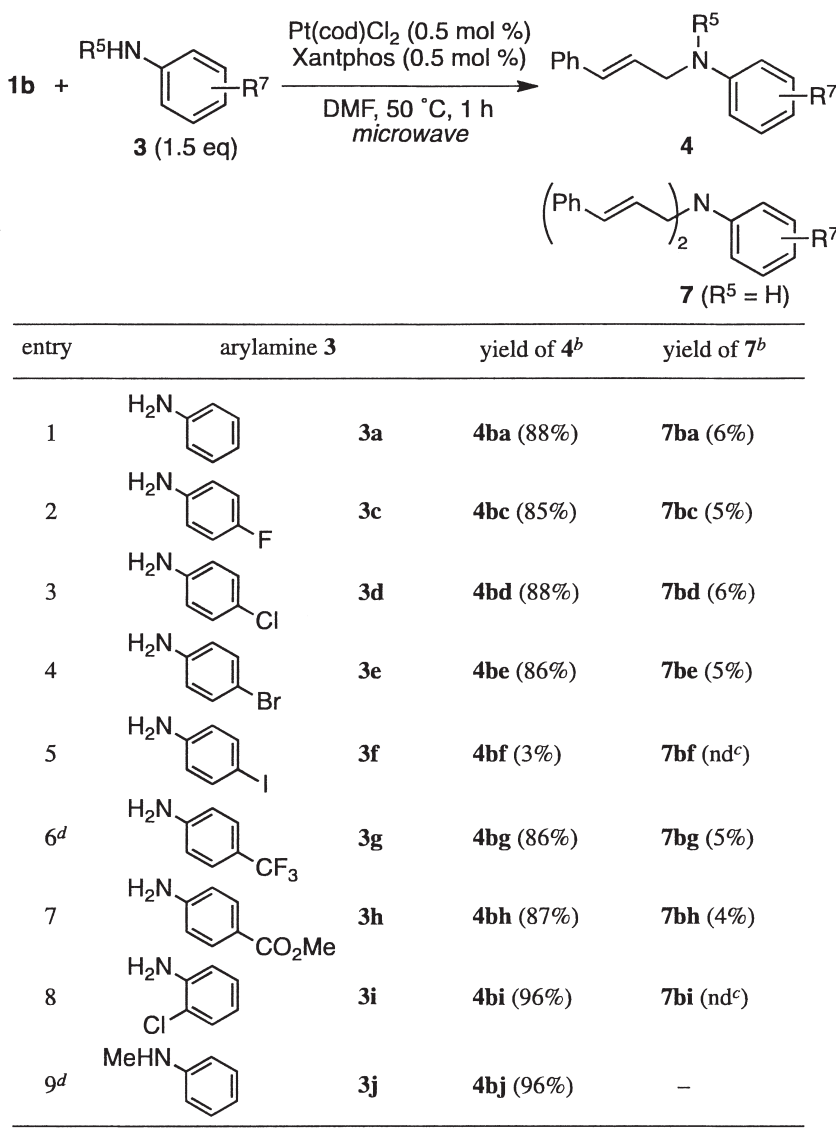

${ }^{a} 2.0 \mathrm{mmol}$ scale, $0.4 \mathrm{~mL}$ of DMF was used. ${ }^{b}$ Isolated yield. ${ }^{c}$ Not detected in the reaction mixture. ${ }^{d}$ Reaction time was $2 \mathrm{~h}$.

4ca $(77 \%)$, 4ca' $(10 \%)$, and 7ca $(6 \%)$ without any undesired $\beta$ $\mathrm{H}$ elimination (entry 4). When $\alpha$-substituted allylic alcohols 1b' (entry 3 ) and 1.' (entry 5) were used, the obtained regio-, stereo-, and monoallylation selectivities were almost the same as those using $\gamma$-substituted allylic alcohols $\mathbf{1 b}$ (entry 2) and 1c (entry 4), respectively, strongly suggesting that the reaction proceeds via $\pi$-allylplatinum intermediates. $\beta$-Methyl-substituted allylic alcohol 1d (entry 6), cyclic allylic alcohol 1f (entry 9), and $\alpha, \alpha$-disubstituted allylic alcohol 1g' (entry 12) were also good substrates for the direct catalytic amination reaction to give the desired products in high yield. On the other hand, the reactions of $\alpha, \gamma$-disubstituted allylic alcohol 1e (entry 7) and $\gamma, \gamma$-disubstituted allylic alcohols $\mathbf{1 g}$ (entry 10) and $\mathbf{~ h}$ (entry 13) resulted in low to moderate yield with partial decomposition of the platinum species. Fortunately, conventional heating instead of microwave irradiation greatly improved the yield of 4ea (entry 8, 91\%), 4ga (entry 11, 85\%), and 4 ha (entry 14,70\%), though these reactions required a longer reaction time (20-48 h). Based on the fact that $\alpha, \alpha^{-}$ disubstituted allylic alcohol 19' reacts much faster than $\gamma, \gamma-$ disubstituted allylic alcohol $\mathbf{1 g}$, the reactivity of the platinum catalysis is more strongly affected by steric congestion around the $\mathrm{C}=\mathrm{C}$ double bond in allylic alcohol than that around the hydroxyl group, demonstrating the importance of the first $\eta^{2}-$ coordination of the $\mathrm{C}=\mathrm{C}$ double bond of allylic alcohols to the platinum atom prior to the generation of the $\pi$-allyl intermediates. Notably, all reactions of various allylic alcohols proceeded with quite high monoallylation selectivity. To the best 
Table 6. Pt-catalyzed direct amination of various allylic alcohols $\mathbf{1} .^{a}$

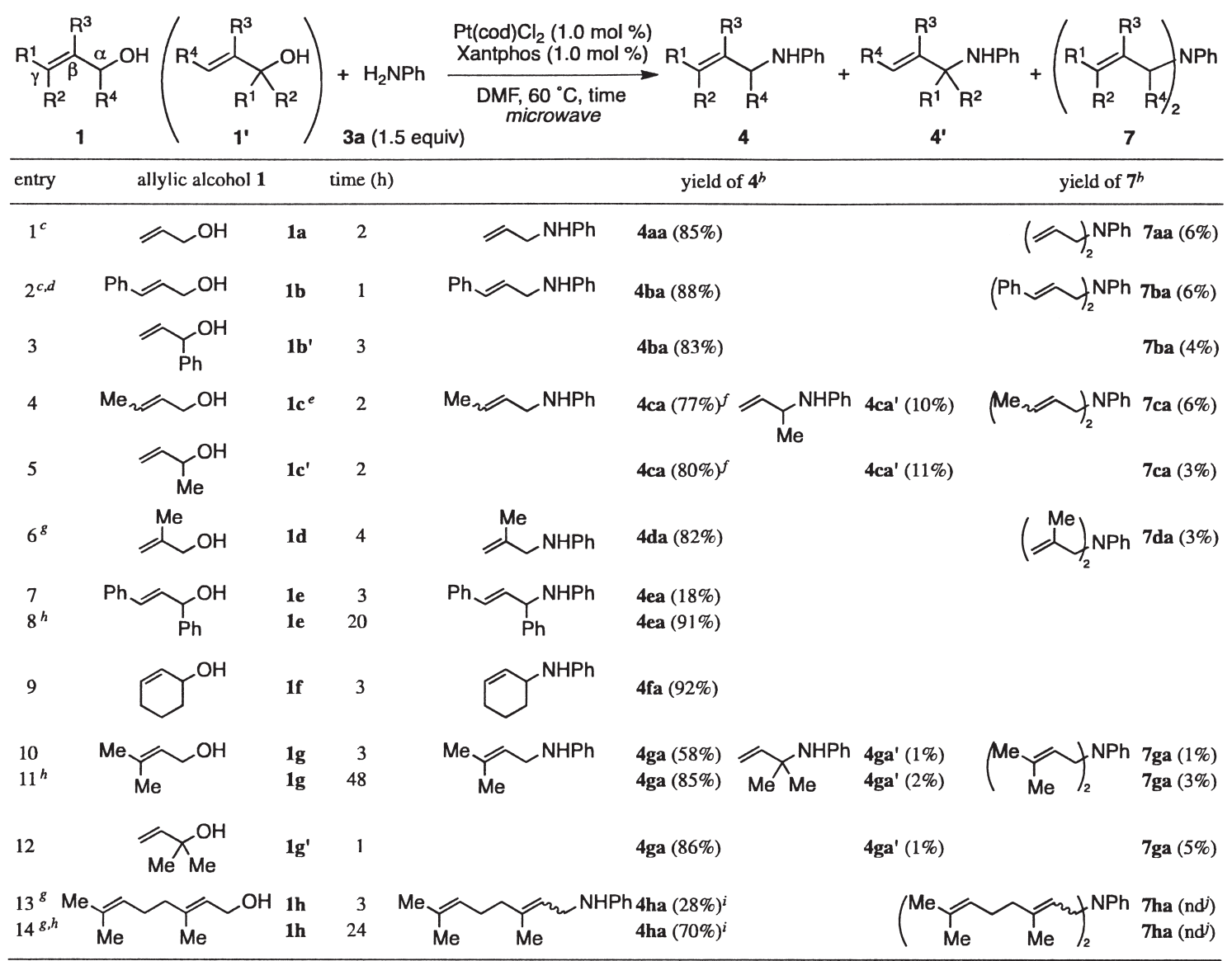

${ }^{a} 2.0 \mathrm{mmol}$ scale, $0.4 \mathrm{~mL}$ of DMF was used. ${ }^{b}$ Isolated yield. ${ }^{c}$ Reaction temperature was $50{ }^{\circ} \mathrm{C} .{ }^{d} 0.5 \mathrm{~mol} \%$ of $\mathrm{Pt}(\mathrm{cod}) \mathrm{Cl}{ }_{2}$ and $0.5 \mathrm{~mol} \%$ of Xantphos were used. ${ }^{e} E / Z$ mixture of $1 \mathrm{c}(E / Z=97 / 3)$ was used. ${ }^{f} \mathbf{4}$ ca was obtained as an $E / Z$ mixture $(10 / 1)$. ${ }^{g}$ Reaction temperature was $80{ }^{\circ} \mathrm{C} .{ }^{h}$ Conventional heating conditions. ${ }^{i}$ 4ha was obtained as an $E / Z$ mixture $(5.8 / 1) .{ }^{j}$ Not detected in the reaction mixture.

of our knowledge, this is the first time that such broad substrate generality (both aryl- and alkyl-substituted allylic alcohols and both arylamines and alkylamines) and high monoallylation selectivity were achieved in this type of direct reaction.

\subsection{Direct Amination with Alkylamines}

The direct substitution of allylic alcohol with alkylamines is more challenging because of its strong tendency towards overreaction. ${ }^{9 b}$ When benzylamine (8a) was used as a nucleophile, the conditions optimized for arylamines resulted in an unsatisfactory low yield of $\mathbf{9 b a}(34 \%)$ and $\mathbf{1 0 b a}(16 \%)$ along with unexpected byproduct 11, which is an allylation product of dimethylamine (Scheme 3). In the reaction of arylamines, the byproduct $\mathbf{1 1}$ was not detected at all, suggesting that dimethylamine would not be generated by simple thermal decomposition of DMF, but was derived by platinum-catalyzed transamidation of DMF in the presence of highly nucleophilic benzylamine (8a). In fact, we confirmed that transamidation of DMF with benzylamine (8a) generated dimethylamine under this reaction condition. Later, this discovery led to the development of ammonium salt-accelerated transamidation, which enable deacylation of unactivated amides to amines under mild conditions. ${ }^{46}$

To avoid such an undesirable side reaction caused by DMF, we re-examined several polar and non-polar solvents other than DMF using benzylamine (8a) as the nucleophile. ${ }^{9 b}$ Among the tested solvents (toluene, 1,2-dichloroethane, chlo-
Scheme 3. Pt-catalyzed direct amination with alkylamine 8a in DMF.

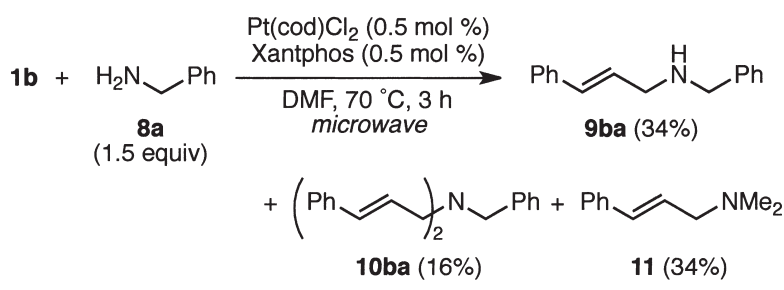

roform, DMSO, and acetonitrile), 1,2-dicloroethane was best; however, the $\mathrm{HCl}$ salt of $\mathbf{8 a}$ was formed, indicating that the chlorinated solvents decomposed the nascent $\operatorname{Pt}(0)$ species. Finally, we decided to use toluene as the solvent to further investigate of the reaction with alkylamines (Table 7). Even after $3 \mathrm{~h}$ microwave irradiation in toluene, direct amination of $\mathbf{1 b}$ with 8 a resulted in only a moderate yield of $\mathbf{9 b a}$ (58\% yield) accompanied by the formation of black precipitates due to partial decomposition of the $\operatorname{Pt}(0)$ species. To stabilize the $\mathrm{Pt}(0)$ species in the reaction mixture, we performed the reaction with an extra amount of the ligand (2.0 equiv. to platinum), although we were concerned that it would generate a less active coordinately saturated $\mathrm{Pt}(0)$ complex $\mathrm{Pt}$ (diphosphine) (Table 7). Surprisingly, despite the structural similarities of Xantphos and DPEphos, each ligand gave completely different 
Table 7. Effects of ligand to platinum ratio on $\mathrm{Pt}$-catalyzed direct amination with alkylamine $\mathbf{8 b} .^{a}$

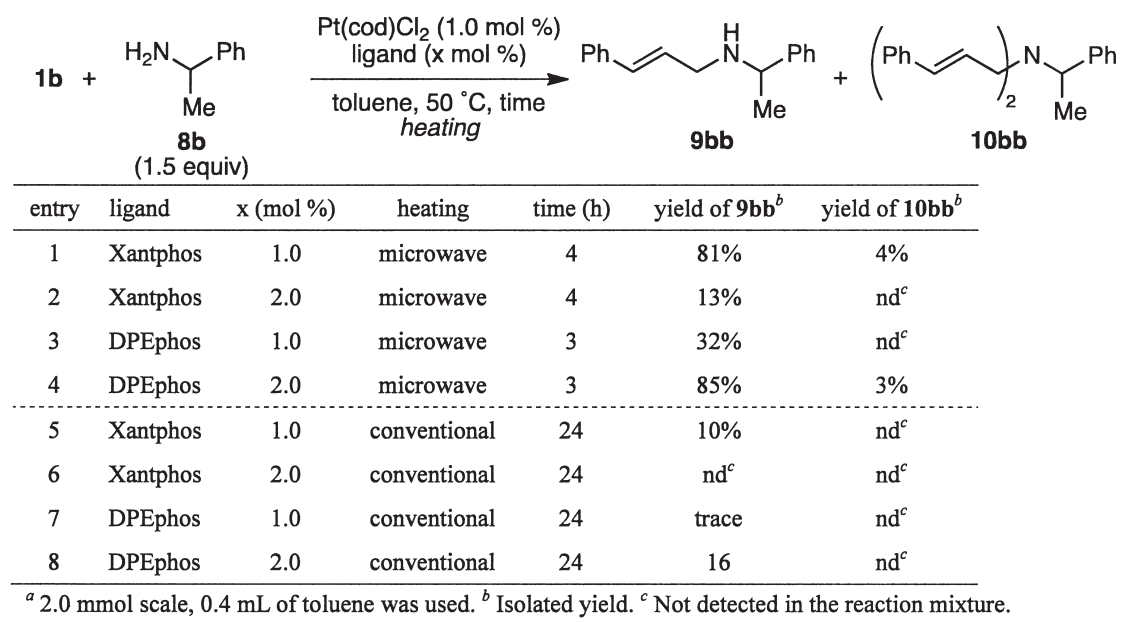

results (entries 1-4). In the case of Xantphos, the use of 2.0 equiv. of ligand to platinum substantially prevented the amination reaction (entry 2, 13\%) with the formation of a yellow precipitate, which was the $\mathrm{Pt}\left(\mathrm{xantphos}_{2}\right.$ complex. The reason for the low reactivity was attributed to the insolubility of this complex in toluene. Moreover, the isolated 18-electron $\mathrm{Pt}(0)$ complex did not promote the reaction of $\mathbf{1 b}$ with $\mathbf{8 b}$ at all. On the other hand, 2.0 equiv. of DPEphos to platinum greatly improved the yield from $32 \%$ (entry 3 ) to $85 \%$ (entry 4 ) without decomposition of the platinum complex. These results clearly indicated that the in situ generated Pt(dpephos) ${ }_{2}$ complex was highly soluble in toluene and easily released one DPEphos ligand to open the coordinately unsaturated active $\mathrm{Pt}(0)$ species. The same tendencies as shown in entries 1-4 were observed in the conventional heating reactions (entries 5-8), but the obtained yields of product $\mathbf{9 b b}$ were much lower even after $24 \mathrm{~h}$.

Under the efficient reaction conditions found for alkylamines (Table 7, entry 4), we performed the reaction with various primary and secondary alkylamines (Table 8). ${ }^{\text {gb }}$ Although 3.0 equiv. of amine was used when sterically less congested primary alkylamines were employed (entries 1-5), monoallylation products 9 were obtained in high yield along with the formation of only small amounts of diallylation products $\mathbf{1 0}$ (entries 1-8). To our knowledge, such high monoallylation selectivity is only achieved by platinum catalysts bearing large bite-angle diphosphine ligands. ${ }^{9 a, 37}$ The reactions also proceeded under solvent-free conditions (entries 3 and 5), resulting in high volumetric productivity and low waste generation. Moreover, direct amination with secondary alkylamines $\mathbf{8 h}-\mathbf{k}$ proceeded quite efficiently to afford the desired products $\mathbf{9 b h}-$ $\mathbf{b k}$, including the antifungal drug naftifine $(\mathbf{9 b j})^{2 \mathrm{a}, \mathrm{b}}$ and the calcium channel blocker flunarizine $(9 \mathbf{b k}),{ }^{2 \mathrm{c}, \mathrm{d}}$ in excellent yields (entries 9-12).

\subsection{Direct Amination with Ammonia}

Ammonia is one of the most important chemical feedstocks for the chemical industry since the discovery of the Harber-Bosch process. ${ }^{47}$ Direct synthesis of nitrogen-containing compounds from ammonia is the most desirable and economical synthetic route, and recent achievements regarding the direct use of ammonia have been remarkable. ${ }^{48}$ Our interest has thus focused on the direct catalytic substitution of allylic

Table 8. Pt-catalyzed direct amination with various alkylamines $8{ }^{a}$

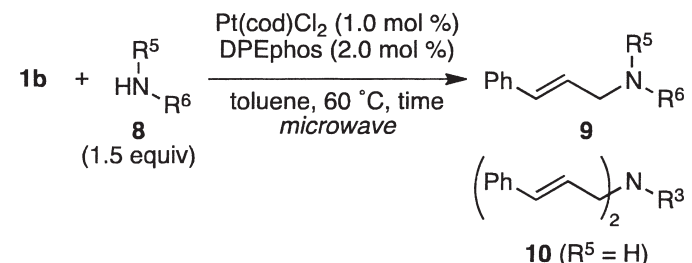

\begin{tabular}{|c|c|c|c|c|c|}
\hline entry & alkylamine 8 & & time (h) & yield of $\mathbf{9}^{b}$ & yield of $1 \mathbf{1 0}^{b}$ \\
\hline $1^{c}$ & $\mathrm{H}_{2} \mathrm{~N} \smile \mathrm{Ph}$ & $8 a$ & 4 & $9 \mathbf{b a}(80 \%)$ & 10ba (10\%) \\
\hline $\begin{array}{l}2^{c} \\
3^{c, d}\end{array}$ & $\mathrm{Me}$ & $\begin{array}{l}8 c \\
8 c\end{array}$ & $\begin{array}{l}4 \\
7\end{array}$ & $\begin{array}{l}9 \mathbf{b c}(60 \%) \\
9 \mathbf{b c}(65 \%)\end{array}$ & $\begin{array}{l}\text { 10bc }(17 \%) \\
\text { 10bc }(6 \%)\end{array}$ \\
\hline $\begin{array}{l}4^{c} \\
5^{c, d}\end{array}$ & & $\begin{array}{l}8 d \\
8 d\end{array}$ & $\begin{array}{l}6 \\
5\end{array}$ & $\begin{array}{l}\text { 9bd (74\%) } \\
\text { 9bd (86\%) }\end{array}$ & $\begin{array}{l}\text { 10bd (5\%) } \\
\text { 10bd (5\%) }\end{array}$ \\
\hline 6 & & $8 e$ & 2 & 9be $(85 \%)$ & 10be $(7 \%)$ \\
\hline 7 & & $8 \mathrm{f}$ & 6 & $9 \mathbf{b f}(77 \%)$ & 10bf $(10 \%)$ \\
\hline 8 & & $8 \mathrm{~g}$ & 6 & $9 \operatorname{bg}(86 \%)$ & 10bg (3\%) \\
\hline 9 & & $8 \mathrm{~h}$ & 3 & 9bh (96\%) & - \\
\hline 10 & & $8 \mathrm{i}$ & 3 & 9bi (98\%) & - \\
\hline 11 & & $8 \mathbf{j}$ & 5 & 9bj (95\%) & - \\
\hline 12 & & $8 \mathbf{k}$ & 4 & 9bk (94\%) & - \\
\hline
\end{tabular}

${ }^{a} 2.0 \mathrm{mmol}$ scale, $0.4 \mathrm{~mL}$ of toluene was used. ${ }^{b}$ Isolated yield. ${ }^{c} 3.0$ equiv. of alkylamine 8 was used. ${ }^{d}$ Solvent-free conditions.

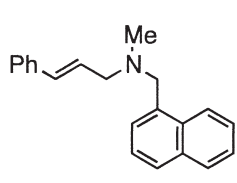

naftifine $(9 \mathrm{bj})$

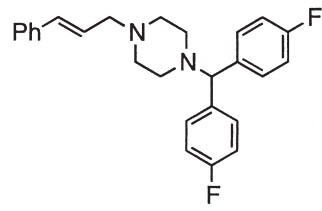

flunarizine (9bk) 
alcohols with ammonia (Scheme $1, \mathbf{1} \rightarrow \mathbf{4}, \mathrm{R}^{5}=\mathrm{R}^{6}=\mathrm{H}$ ) as the most rational synthetic protocol for primary allylamines in terms of the environmental and economic benefit. ${ }^{6}$ The direct use of ammonia as a nucleophile has already been applied for the amination of allylic esters and carbonates $(\mathbf{2} \rightarrow \mathbf{4})$ using a $\mathrm{Pd}$-catalyst by Kobayashi et al. ${ }^{49}$ and the enantioselective amination of allylic carbonates using a chiral $\mathrm{Ir}-$ catalyst by Hartwig et al. ${ }^{50}$ Recently, Carreira et al. reported that optically active allylamines were prepared by the $\mathrm{Ir}$-catalyzed stereospecific substitution reaction of optically active branched allylic alcohols with sulfamic acid as an ammonia equivalent. ${ }^{51}$ In contrast, ammonia has never been used for the direct transformation of allylic alcohols into the corresponding primary allylamines, because the nucleophilicity of ammonia is much lower than that of alkylamines.

Our search was conducted for the allylic amination reaction of $\mathbf{1 b}$ with degassed aq. ammonia as a test reaction using $\mathrm{PtCl}_{2}$ (cod)/DPEphos system, and the results are summarized in Table 9. ${ }^{9 \mathrm{c}}$ When the reaction using $28 \%$ aq. ammonia (30 equiv., 1:5 [v/v] mixture of aq. ammonia and 1,4-dioxane) was conducted at $100{ }^{\circ} \mathrm{C}$ for $24 \mathrm{~h}$, the corresponding linear monoallylated amine $\mathbf{1 1 b}$ was obtained in $60 \%$ yield along with diallylated amine 12b $(\mathbf{1 1 b} \mathbf{b} \mathbf{1 2} \mathbf{b}=82: 18)$ with water as the sole co-product (entry 1). Branched allylamines was not detected in the ${ }^{1} \mathrm{H}$ NMR spectrum of the crude products. Because product 11b has much higher nucleophilicity than ammonia and thus over-reaction of $\mathbf{1 1} \mathbf{b}$ with $\mathbf{1 b}$ to $\mathbf{1 2 b}$ proceeds more readily, the monoallylation selectivity was lower than that when alkylamine was used as the nucleophile. ${ }^{9 a}$ This moderate monoallylation selectivity was improved to $90: 10$ by increasing the amount of ammonia (90 equiv.) to afford the desired product 11b in 74\% yield (entry 3 ). Unexpectedly, the reaction with excess amounts of ammonia resulted in a lower yield due to partial deactivation of the Pt catalyst at a higher concentration of ammonia (entry 4$)$. At a lower reaction temperature $\left(80{ }^{\circ} \mathrm{C}\right)$, no reaction proceeded (entry 5). Under the same reaction conditions as for entry 3, Pt-Xantphos catalyst systems $(\mathrm{P} / \mathrm{Pt}=4$ and 2) were less efficient and $\mathbf{1 1 b}$ was obtained in poor yield (34\% and 29\%, respectively; entries 6 and 7). Solvent effects were surveyed using a 1:1 [v/v] ratio of aq. ammonia and solvents. In THF and DME, 11b was obtained in moderate yields, $52 \%$ and $59 \%$, respectively (entries 8 and 9 ), whereas, in toluene, no reaction proceeded because of the biphasic reaction mixture (entry 10). Coordinative solvents such as acetonitrile and DMSO afforded the products in lower yields (entries 11 and 12). In DMF medium, $N, N$-dimethyl-3-phenylprop-2en-1-amine was formed as the major product and a trace amount of the desired primary allylamine was detected in the crude reaction mixture (entry 13). ${ }^{9 \mathrm{~b}}$ In protic methanol media, the results were similar (entry 14) to those obtained in 1,4dioxane. Other alcohols were less effective than $\mathrm{MeOH}$ in terms of the yield of $\mathbf{1 1 b}$. Furthermore, the reaction in aq. ammonia without organic solvent resulted in a very low yield of 11b along with the recovered starting material (92\%; entry 15). Finally, it is intriguing that the Pt-DPEphos in the mixed solvent system of aq. ammonia, 1,4-dioxane, and $\mathrm{MeOH}$ in a 3:2:1 [v/v/] proportion provided the best yield $(79 \%)$ with high monoallylation selectivity (11b:12b=91:9; entry 16) as the best conditions. The reaction using only $0.5 \mathrm{~mol} \%$ of catalyst also proceeded smoothly, although the yield of 11b was slightly lower (entry 17).
Table 9. Optimization of the reaction conditions for direct amination of ammonia. ${ }^{a}$

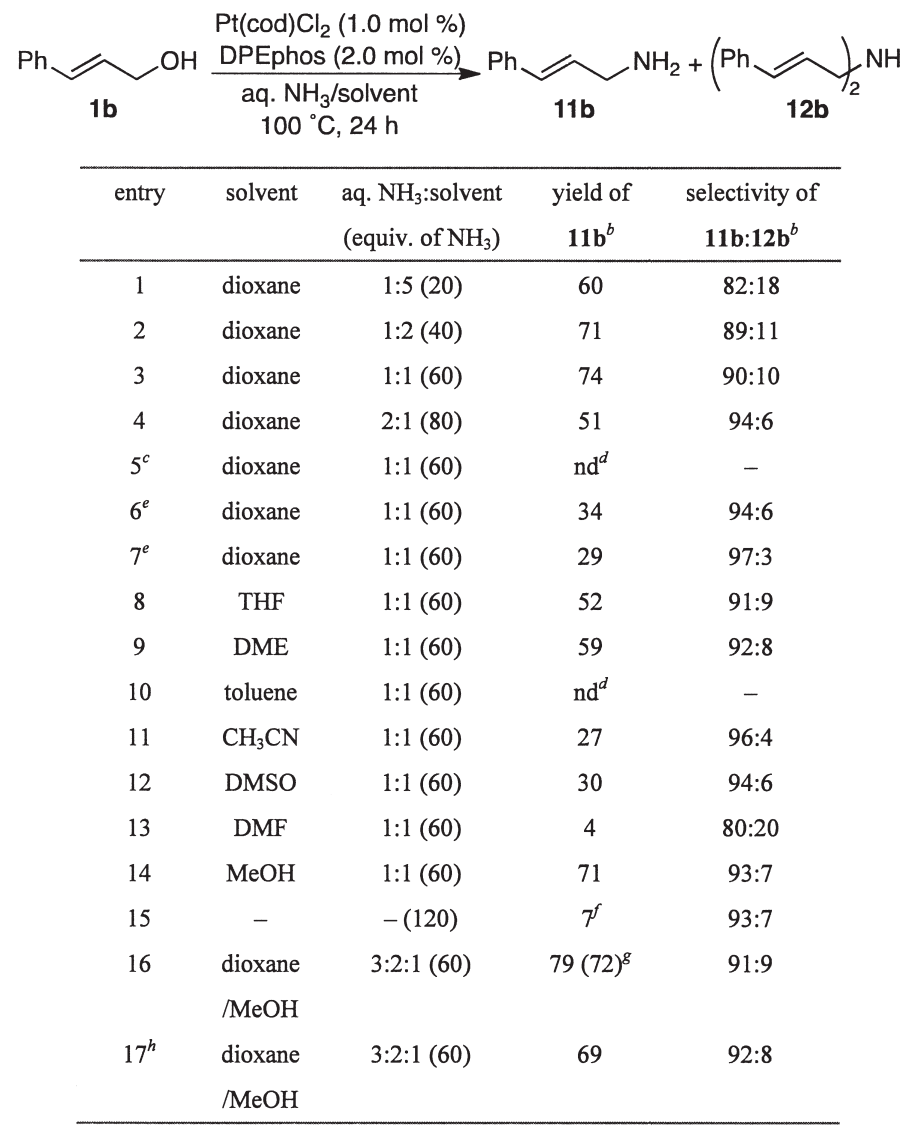

\footnotetext{
${ }^{a} 0.5 \mathrm{mmol}$ scale, $28 \%$ aq. $\mathrm{NH}_{3}$ and solvent (total volume $6.0 \mathrm{~mL}$ ) was used in sealed tube. ${ }^{b}$ Determined by ${ }^{1} \mathrm{H}$ NMR analysis. ${ }^{c}$ Reaction temp. was $80{ }^{\circ} \mathrm{C} .{ }^{d}$ Not detected in the reaction mixture. ${ }^{e}$ Xantphos was used
} instead of DPEphos. $\mathrm{P} / \mathrm{Pt}=4$ (entry 6 ) and 2 (entry 7$).{ }^{f} \mathbf{1 b}$ was recovered

The use of aq. ammonia is essential for achieving the high yield of 11b and high monoallylation selectivity. In fact, the reaction of $\mathbf{1 b}$ with gaseous ammonia dissolved in 1,4-dioxane afforded $\mathbf{1 1 b}$ in poor yield (11\%) with contamination of a diallylated amine 12b (11\%) and a tertiary amine 13b (8\%) (Scheme 4).

Scheme 4. Pt-catalyzed direct amination with gaseous ammonia.

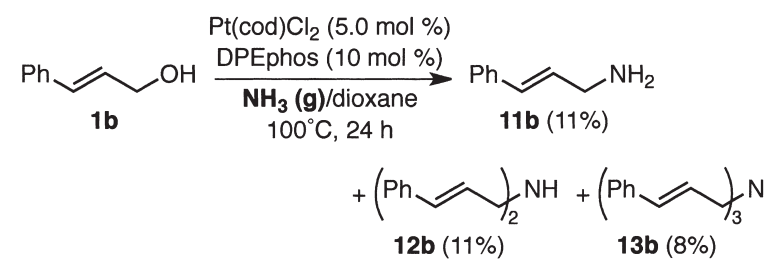

Because the reaction conditions were optimized for amination by aqueous ammonia, the scope of allylic alcohols 1 was assayed and the results are summarized in Table $10 .{ }^{9 \mathrm{c}}$ Direct amination of a series of cinnamyl alcohol derivatives $\mathbf{1} \mathbf{i}-\mathbf{m}$ with aq. ammonia afforded the corresponding primary monoallylamines 11i-m with high yield and high selectivity (entries 1-5). Branched allylic alcohols were efficiently converted to primary allylamines with a similar distribution of 11/12 (entries 7-9). Sterically congested 1,3-disubstituted allylic alcohols were good substrates for the present catalysis, 
Table 10. Pt-catalyzed direct amination of various allylic alcohols with aqueous ammonia. ${ }^{a}$

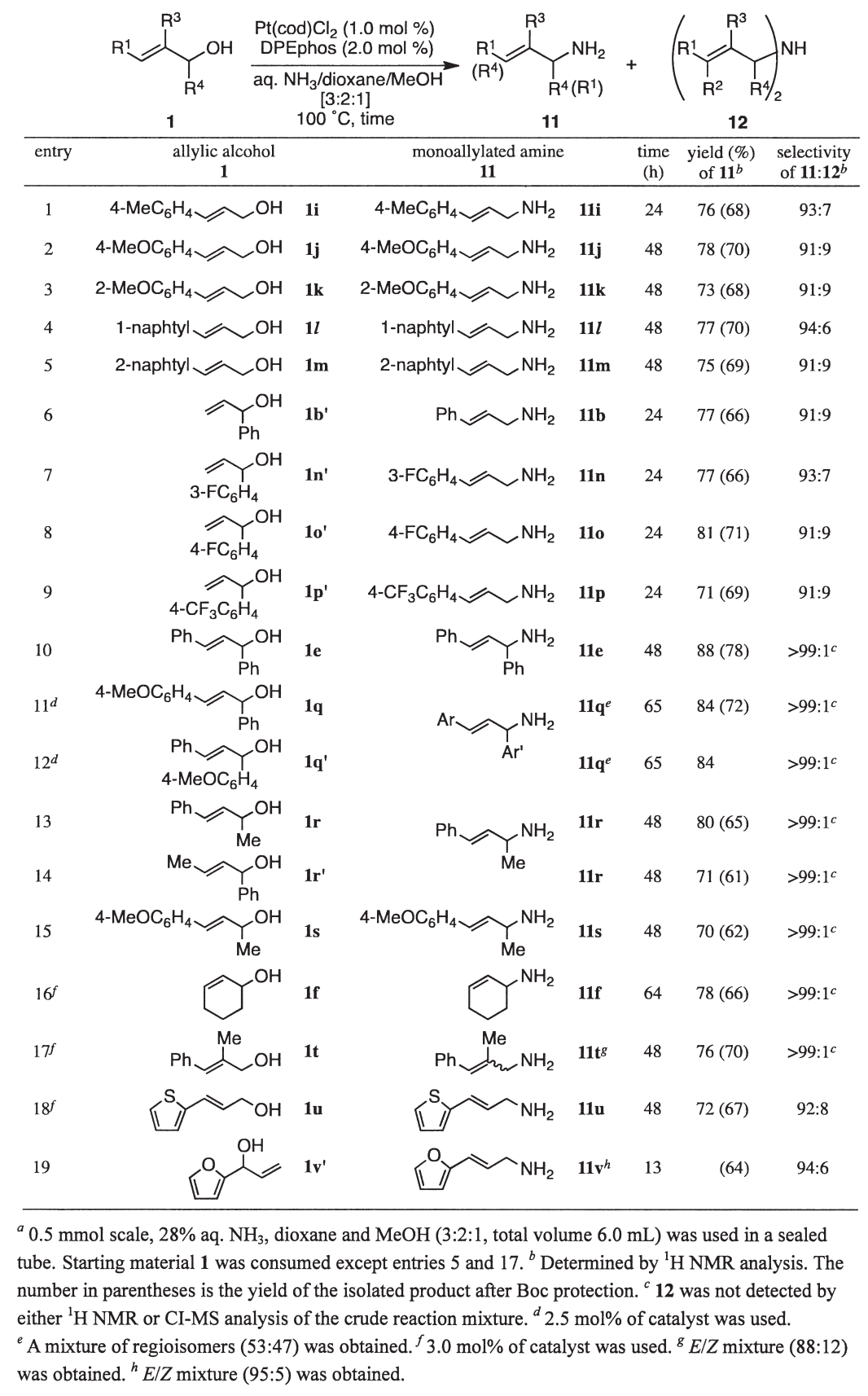

and, notably, the corresponding diallyl products were not detected by ${ }^{1} \mathrm{H}$ NMR or CI-MS analysis of the crude reaction mixture (entries 10-12). The reactions of alkyl-substituted allylic alcohol also resulted in the good conversion of allylic alcohols to the corresponding monoallylated amines with quite high 11/12 selectivity ( $>99$ :1; entries $13-15)$. Since both cyclic and $\beta$-substituted allylic alcohols 1f (entry 16) and $\mathbf{1 t}$ (entry 17) were less reactive substrates, their reactions required the use of $3.0 \mathrm{~mol} \%$ of catalyst loading. Additionally, highly unstable $\gamma$-thiophene and furan substituted allylic alcohols $\mathbf{1 u}$ (entry 18) and $\mathbf{1 v}$ (entry 19) were also successfully converted to the corresponding primary amines without any decomposition.

\section{Mechanistic Studies}

We revealed a plausible catalytic cycle of the platinum- catalyzed direct amination of allylic alcohol to be as depicted in Scheme 5 based on our intensive experiments including ${ }^{1} \mathrm{H}$ and ${ }^{31} \mathrm{P}\left\{{ }^{1} \mathrm{H}\right\}$ NMR analysis, isolation of several catalytic intermediates, confirmation of the structure of $\left[\operatorname{Pt}\left(\eta^{3}\right.\right.$-allyl)(xantphos)]OTf $\left(\mathbf{D}_{\text {отf }}\right)$ by $\mathrm{X}$-ray crystallographic analysis, and crossover experiments. ${ }^{9 b}$ Since we described above that $\operatorname{Pt}(0)$ species were less effective catalyst precursors and $\mathrm{Pt}(\operatorname{cod}) \mathrm{Cl}_{2}$ was found to be the best precursor, ${ }^{9 a, b}$ we first investigated the compound that reduced $\mathrm{Pt}(\mathrm{II})$ to $\mathrm{Pt}(0)$. Candidate reagents are phosphine ligand, amine, or allylic alcohol. Among them, we confirmed that the $\mathrm{Pt}(\mathrm{II})$ species was reduced to the $\mathrm{Pt}(0)$ species by allylic alcohol 1 through $\beta-\mathrm{H}$ elimination of alkoxy$\mathrm{Pt}(\mathrm{II})$ species to give a $\mathrm{Pt}(0)$ complex, $\mathrm{Pt}\left(\eta^{2}-\mathrm{C}_{3} \mathrm{H}_{5} \mathrm{OH}\right)($ diphosphine) (B), which was alternatively prepared and isolated by reduction of $\mathrm{Pt}$ (xantphos) $\mathrm{Cl}_{2}$ (A) with $\mathrm{NaBH}_{4}$ in the presence of allyl alcohol (1a) in 94\% yield, along with $\alpha, \beta$-unsaturated 
Scheme 5. Proposed catalytic cycle of the platinum-catalyzed direct amination of allylic alcohol. ${ }^{a, b}$

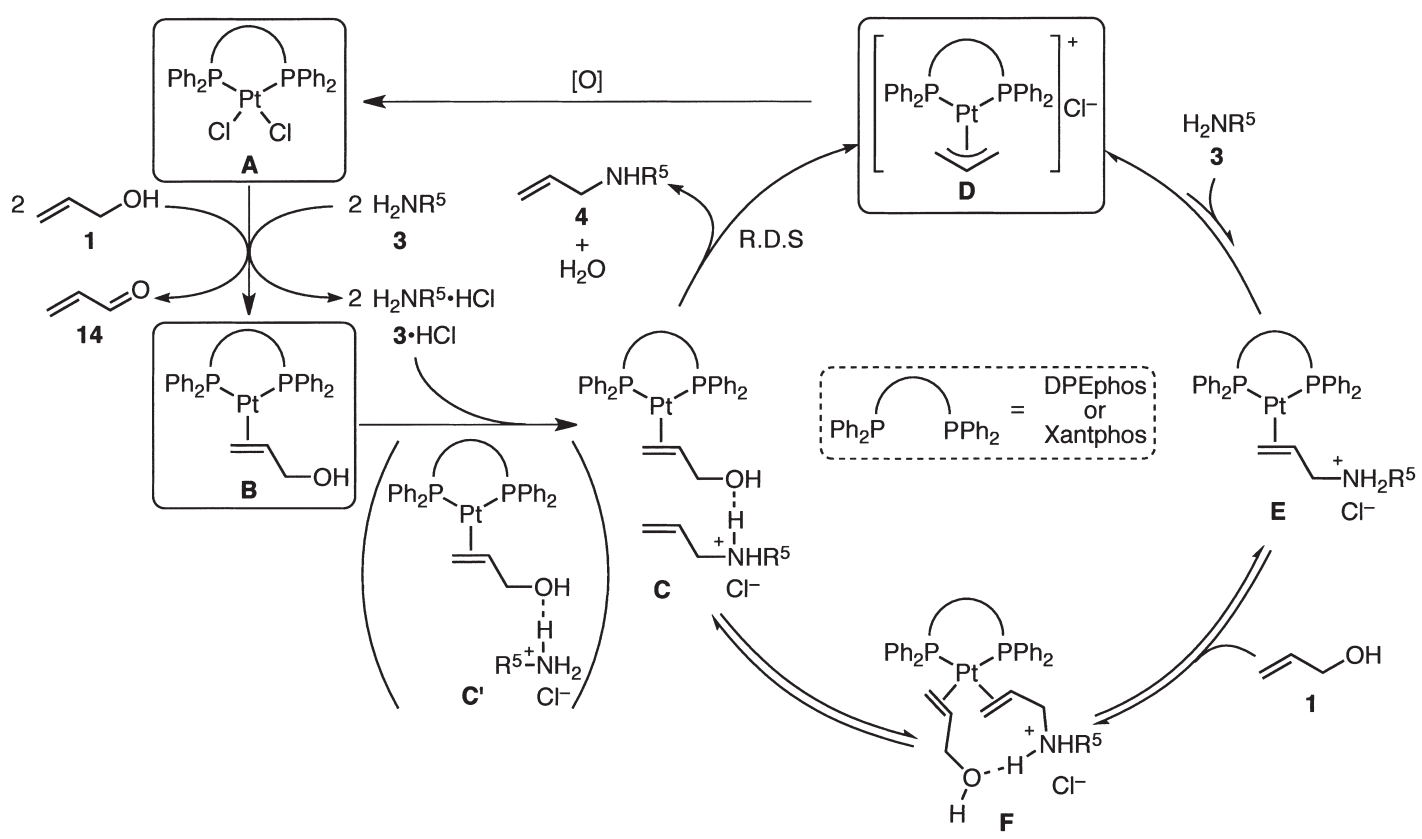

${ }^{a}$ Substituents of allylic alcohol 1 are omitted for clarity. ${ }^{b}$ Structurally characterized complexes are boxed.

aldehyde 14. In the catalytic cycle, the following species is a $\pi^{-}$ allyl complex: we synthesized and isolated $\mathbf{D}_{\text {отf }}$ in $84 \%$ yield by the reaction of $\mathrm{Pt}$ (xantphos) $\mathrm{Cl}_{2}$ (A), allyltributylstannane (1.0 equiv.), and AgOTf (1.0 equiv.). The structure of $\mathbf{D}_{\text {otf }}$ confirmed by $\mathrm{X}$-ray crystallographic analysis is shown in Figure 1 . The bite-angle of the crystal $\left(107^{\circ}\right)$ is almost the same as that obtained by density functional theory calculations (Table $2,108^{\circ}$ ), and there is no direct interaction between the $\mathrm{Pt}$ atom and the oxygen atom of the ligand.

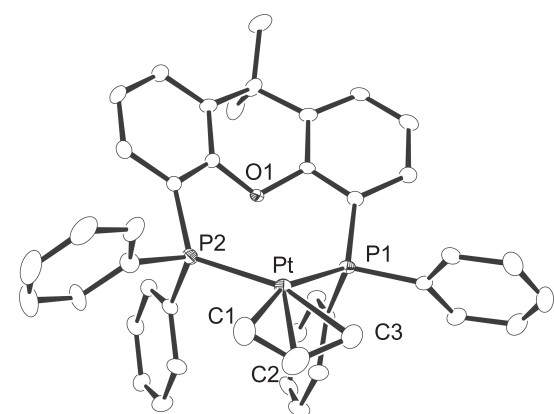

Figure 1. ORTEP drawing of $\left[\operatorname{Pt}\left(\eta^{3}\right.\right.$-allyl)(xantphos) $\mathrm{OTf}\left(\mathbf{D}_{\text {OTf }}\right)$ with thermal ellipsoids at the $50 \%$ probability level. The hydrogen atoms, counter anions, and solvent are omitted for clarity.

The catalyst activities of $\mathbf{B}$ and $\mathbf{D}_{\text {OTf }}$ were checked by the reaction of 1a and 3a. Since both complexes promoted the reaction to give the product (Scheme 6), these complexes are proved to be involved in the catalytic cycle. Notable point is that the reactivity of these complexes differed from that of the $\mathrm{Pt}(\mathrm{cod}) \mathrm{Cl}_{2}-$ Xantphos system. Under conventional heating conditions at $50{ }^{\circ} \mathrm{C}$, complex $\mathbf{B}$ required $24 \mathrm{~h}$ for full conversion, while the reactions using $\mathrm{Pt}(\operatorname{cod}) \mathrm{Cl}_{2}-\mathrm{Xantphos}$ and $\mathbf{D}_{\text {отf }}$ completed in $10 \mathrm{~h}$ and $2 \mathrm{~h}$, respectively. The higher catalyst activities of $\mathrm{Pt}(\operatorname{cod}) \mathrm{Cl}_{2}-\mathrm{Xantphos}$ and $\mathbf{D}_{\text {OTf }}$ than $\mathbf{B}$ might be due to the ammonium salts $\mathrm{HNR}^{5} \mathrm{R}^{6} \cdot \mathrm{HCl}$ and $\mathrm{H}_{2} \mathrm{NR}^{5} \mathrm{R}^{6}$. HOTf, which could potentially act as more efficient activators of the hydroxyl group to accelerate the elimination of hydroxide through hydrogen bonding of ammonium salts with a hydroxyl group of allylic alcohol $(\mathbf{C} \rightarrow \mathbf{D})$. In contrast, the addition of $\mathrm{NH}_{4} \mathrm{Cl}$ (2.0 equiv. to substrate) to the direct amination with ammonia under aqueous conditions did not significantly improve the catalytic activity. ${ }^{9 \mathrm{c}}$ Thus, it is likely that the aqueous condition contributed to the hydrogen bonding effects of water to activate the hydroxyl group of allylic alcohols. ${ }^{24}$

Scheme 6. Catalytic activities of $\mathrm{Pt}\left(\eta^{2}-\mathrm{C}_{3} \mathrm{H}_{5} \mathrm{OH}\right)($ xantphos) (B) and $\left[\operatorname{Pt}\left(\eta^{3}\right.\right.$-allyl)(xantphos)]OTf ( $\left(\mathbf{D}_{\text {OTf }}\right)$.

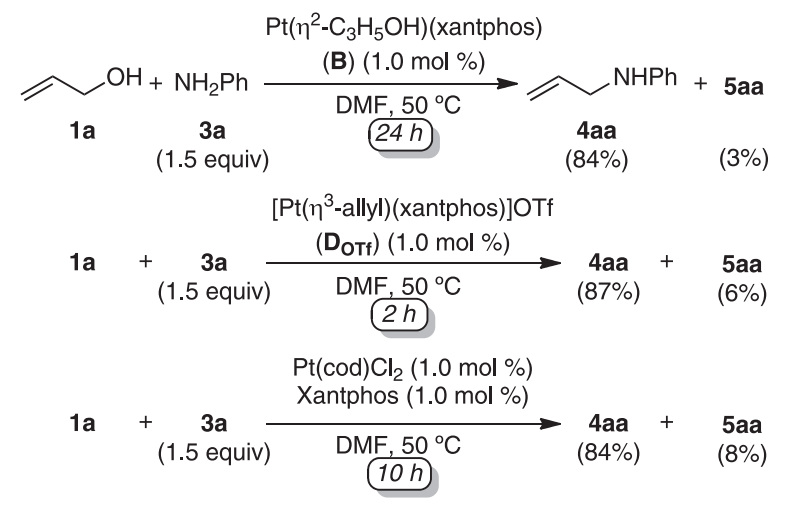

The addition of 2.0 equiv. $\mathbf{4 a a} \cdot \mathrm{HCl}$ salt to the $\mathrm{Pt}(0)$ complex $\mathbf{B}$ at room temperature led to the exclusive formation of $\left[\operatorname{Pt}\left(\eta^{3}\right.\right.$-allyl)(xantphos) $] \mathrm{Cl}$ (D) within $5 \mathrm{~min}$; however, only free allyl alcohol (1a) was detected, and not free $N$-allylaniline (4aa) or water, strongly suggesting that $\pi$-allylplatinum complex D was not generated through the elimination of water from the allyl alcohol (1a) coordinated to the $\operatorname{Pt}(0)$ atom $(\mathbf{C} \rightarrow \mathbf{D}$, clockwise direction), but rationally through the elimination of aniline (3a) from $N$-allylaniline (4aa) $(\mathbf{C} \rightarrow \mathbf{F} \rightarrow \mathbf{E} \rightarrow \mathbf{D}$, counterclockwise direction). The existence of this rapid retro reaction was further supported by crossover experiments. ${ }^{9 \mathrm{~b}}$

${ }^{1} \mathrm{H}$ and ${ }^{31} \mathrm{P}\left\{{ }^{1} \mathrm{H}\right\}$ NMR spectroscopic monitoring of a mix- 
ture of $\mathbf{D}_{\text {OTf }}$ and 12.0 equiv. of $\mathbf{3 a}$ in $\mathrm{DMF}-d_{7}$ indicated that almost no reaction occurred even after $6 \mathrm{~h}$ of heating at $50{ }^{\circ} \mathrm{C}$. In contrast, when allyl alcohol (1a) was added to this mixture with $\mathbf{3 a}$, clear conversion of $\mathbf{1 a}$ to the allylated products $\mathbf{4 a a}$ $(62 \%)$ and 5 aa $(38 \%)$ was detected by ${ }^{1} \mathrm{H}$ NMR, though only the starting $\mathbf{D}_{\text {OTf }}$ was detected on ${ }^{31} \mathrm{P}\left\{{ }^{1} \mathrm{H}\right\}$ NMR spectroscopy. Recently, le Floch and co-authors reported that, in the case of $\left[\mathrm{Pt}\left(\eta^{3}\right.\right.$-allyl)(dpp-xantphos)] $\mathrm{PF}_{6}$, the addition of benzylamine (8a) led to the formation of a new complex, tentatively assigned as $\mathrm{Pt}\left(\eta^{2}-\mathrm{H}_{2} \mathrm{C}=\mathrm{CHCH}_{2} \mathrm{NH}_{2} \mathrm{Bn}^{+} \mathrm{PF}_{6}^{-}\right)(\mathrm{dpp}$-xantphos $) \mathbf{E} .^{37}$ In sharp contrast to their results, our results suggested that (1) complexes $\mathbf{D}, \mathbf{E}, \mathbf{F}$, and $\mathbf{C}$ were in rapid equilibrium, even at room temperature; (2) among them, $\mathbf{D}$ was the most stable species even in the presence of excess amounts of nucleophile $\mathbf{3}$; and (3) the formation of $\mathbf{D}$ from $\mathbf{C}$ through the elimination of water $(\mathbf{C} \rightarrow \mathbf{D})$ was the rate-determining step of this catalytic cycle and required a reaction temperature of $50{ }^{\circ} \mathrm{C}$.

The excellent high monoallylation selectivity in the present Pt catalysis likely originates from the selective attack of the smaller amine nucleophile 3 on the $\pi$-allylplatinum intermediate, where the large bite-angled diphosphine ligand DPEphos or Xantphos produced a congested environment around the Pt center, compared with the corresponding monoallylated amine 4 (Scheme 7).

Scheme 7. Plausible mechanism for high monoallylation selectivity.

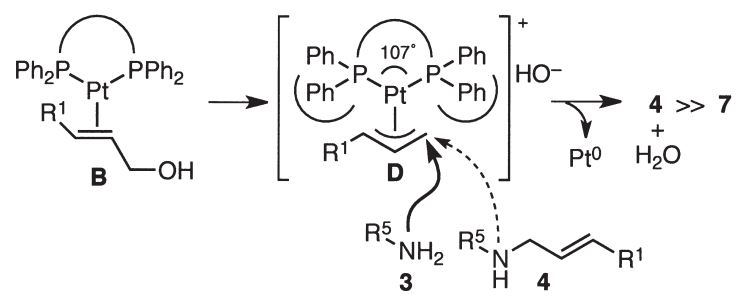

\section{Conclusions}

Here we introduced the development of a Pt-catalyzed direct amination of allylic alcohols with amine including the smallest nitrogen nucleophile ammonia without prior activation of the allylic alcohol. ${ }^{9}$ Overall, this $\mathrm{Pt}$-catalytic system provides a new protocol for the direct amination of allylic alcohols with a wide substrate scope, offering an efficient direct access to a variety of primary, secondary, and tertiary monoallylamines in an atom-economical and environmentally benign manner. Further investigation of the application to the use of other types of nucleophile, and of the scope of the syntheses of highly functionalized bioactive natural and unnatural compounds, along with the studies on enantioselective variants, one-pot sequential reaction, and flow systems are ongoing in our group.

\section{Acknowledgements}

We deeply acknowledge our coworkers, Dr. Masaru Utsunomiya, Yoshiki Miyamoto, Junji Ipposhi, Dr. Kalpataru Das, Yasuhito Nakahara, Ryozo Shibuya, and Nicolas Germain, for their extensive contributions to this work. This work was supported by Encouragement of Young Scientists (A) from Japan Society for the Promotion of Science, a Grant-in-Aid for Science Research in a Priority Area (No. 20037040, "Chemistry of Concerto Catalysis") and Grant-in-Aid for Scientific Research (B) (21390003) from the Ministry of Edu- cation, Culture, Sports, Science and Technology, Japan, The Core Research for Evolutional Science and Technology (CREST) program of the Japan Science and Technology Agency (JST), The Grand-in-Aid for Scientific Research on Innovative Area "Reaction Integration” (No. 2105), the Uehara Memorial Foundation, and Mitsubishi Chemical Corporation Foundation.

\section{References and Notes}

1) For reviews, see: (a) Cheikh, R. B.; Chaabouni, R.; Laurent, A.; Mison, P.; Nafti, A. Synthesis 1983, 685. (b) Johannsen, M.; Jørgensen, K. A. Chem. Rev. 1998, 98, 1689. (c) Trost, B. M.; Crawley, M. L. Chem. Rev. 2003, 103, 2921.

2) (a) Petranyi, G.; Ryder, N. S.; Stütz, A. Science 1984, 224, 1239. (b) Kanno, H.; Taylor, R. J. K. Tetrahedron Lett. 2002, 43, 7337. (c) Olesen, J. J. Neurol 1991, 238, S23. (d) Marín, M. T.; Margarit, M. V.; Salcedo, G. E. Il Farmaco 2002, 57, 723.

3) For reviews, see: (a) Akutagawa, S.; Tani, K. In Catalytic Asymmetric Synthesis, 2nd ed.; Ojima, I., Ed.; Wiley-VCH: New York, 2000. (b) Noyori, R. In Asymmetric Catalysis in Organic Synthesis; WileyVCH: New York, 1994; Chapter 3, p 95.

4) For reviews, see: (a) Handbook of Metathesis, Vols 1-3, Grubbs, R. H., Ed.; Wiley-VCH: Weinheim, 2003. (b) Nicolaou, K. C.; Bulger, P. G., Sarlar, D. Angew. Chem. Int. Ed. 2005, 44, 4490.

5) For reviews, see: (a) Tsuji, J. Transition Metal Reagents and Catalysis; Wiley-VCH: Weinheim, 2000. (b) Trost, B. M.; Lee, C. In Catalytic Asymmetric Synthesis, 2nd ed.; Ojima, I., Ed.; Wiley-VCH: New York, 2000. (c) Trost, B. M.; Crawley, M. L. Chem. Rev. 2003, 103, 2921.

6) For review, see: (a) Muzart, J. Tetrahedron 2005, 61, 4179. (b) Tamaru, Y. Eur. J. Org. Chem. 2005, 2647. (c) Muzart, J. Eur. J. Org. Chem 2007, 3077.

7) Lewis acid-catalyzed direct substitution of allylic, propargylic, and benzylic alcohols with electron-deficient nitrogen nucleophiles were reported. For representative examples, see: (a) Nishibayashi, Y.; Milton, M. D.; Inada, Y.; Yoshikawa, M.; Wakiji, I.; Hidai, M.; Uemura, S. Chem. Eur. J. 2005, 11, 1433. (b) Terrasson, V.; Marque, S.; Georgy, M.; Campagne, J.-M.; Prim, D. Adv. Synth. Catal. 2006, 348, 2063. (c) Qin, H.; Yamagiwa, N.; Matsunaga, S.; Shibasaki, M. Angew. Chem. Int. Ed. 2007, 46, 409. (d) Guo, S.; Song, F.; Liu, Y. Synlett 2007, 964. (e) Reddy, C. R.; Madhavi, P. P.; Reddy, A. S. Tetrahedron Lett. 2007, 48, 7169. (f) Sreedhar, B.; Reddy, P. S.; Reddy, M. A.; Neelima, B.; Arundhathi, R. Tetrahedron Lett. 2007, 48, 8174. (g) Jana, U.; Maiti, S.; Biswas, S. Tetrahedron Lett. 2008, 49, 858. (h) Wang, G.-W.; Shen, Y.-B.; Wu, X.-L. Eur. J. Org. Chem. 2008, 4367. (i) Huang, W.; Shen, Q.-S.; Wang, J.-L.; Zhou, X.-G. Chin. J. Chem. 2008, 26, 729 .

8) (a) Ohshima, T.; Nakahara, Y.; Ipposhi, J.; Miyamoto, Y.; Mashima, K. Chem. Commun. 2011, 47, 8322. (b) Ohshima T.; Ipposhi J.; Nakahara Y.; Shibuya R.; Mashima K. Adv. Synth. Catal. accepted.

9) (a) Utsunomiya, M.; Miyamoto, Y.; Ipposhi, J.; Ohshima, T.; Mashima, K. Org. Lett. 2007, 9, 3371. (b) Ohshima, T.; Miyamoto, Y.; Ipposhi, J.; Nakahara, Y.; Utsunomiya, M.; Mashima, K. J. Am. Chem. Soc. 2009, 131, 14317. (c) Das, K.; Shibuya, R.; Nakahara, Y.; Germain, N.; Ohshima, T.; Mashima, K. Angew. Chem. Int. Ed. 2012, 51,150 .

10) Trost, B. M. Science 1991, 254, 1471.

11) Lu, X.; Lu, L.; Sun, J. J. Mol. Catal. 1987, 41, 245.

12) Lu, X.; Jiang, X.; Tao, X. J. Organomet. Chem. 1988, 344, 109.

13) (a) Masuyama, Y.; Takahara, J. P.; Kurusu, Y. J. Am. Chem. Soc. 1988, 110, 4473. (b) Masuyama, Y.; Kagawa, M.; Kurusu, Y. Chem. Lett. 1995, 1121

14) Lumin, S.; Falck, J. R.; Capdevila, J.; Karara, A. Tetrahedron Lett. 1992, 33, 2091

15) (a) Itoh, K.; Hamaguchi, N.; Miura, M.; Nomura, M. J. Chem. Soc., Perkin Trans. 1 1992, 2833. (b) Satoh, T.; Ikeda, M.; Miura, M.; Nomura, M. J. Org. Chem. 1997, 62, 4877. (c) Yang, S.-C.; Hung, C.-W. J. Org. Chem. 1999, 64, 5000. (d) Yang, S.-C.; Tsai, Y.-C.; Shue, Y.-J. Organometallics 2001, 20, 5326. (e) Shue, Y.-J.; Yang, S.-C.; Lai, H.-C. Tetrahedron Lett. 2003, 44, 1481.

16) Stary, I.; Stará, I. G.; Kocovsky, P. Tetrahedron Lett. 1993, 34, 179

17) Tsay, S.; Lin, L. C.; Furth, P. A.; Shum, C. C.; King, D. B.; Yu, S. F.; Chen, B.; Hwu, J. R. Synthesis 1993, 329.

18) Sakamoto, M.; Shimizu, I.; Yamamoto, A. Bull. Chem. Soc. Jpn. 1996, 69, 1065 . 
19) (a) Kimura, M.; Tomizawa, T.; Horino, Y.; Tanaka, S.; Tamaru, Y. Tetrahedron Lett. 2000, 41, 3627. (b) Kimura, M.; Horino, Y.; Mukai, R.; Tanaka, S.; Tamaru, Y. J. Am. Chem. Soc. 2001, 123, 10401. (c) Kimura, M.; Futamata, M.; Shibata, K.; Tamaru, Y. Chem. Commun. 2003, 234.

20) Yang, S.-C.; Hsu, Y.-C.; Gan, K.-H. Tetrahedron, 2006, 62, 3949.

21) Yamashita, Y.; Gopalarathnam, A.; Hartwig, J. F. J. Am. Chem. Soc. 2007, 129, 7508 .

22) (a) Ozawa, F.; Okamoto, H.; Kawagishi, S.; Yamamoto, S.; Minami, T.; Yoshifuji, M. J. Am. Chem. Soc. 2002, 124, 10968. (b) Ozawa, F.; Ishiyama, T.; Yamamoto, S.; Kawagishi, S.; Murakami, H.; Yoshifuji, M. Organometallics 2004, 23, 1698.

23) Kayaki, Y.; Koda, T.; Ikariya, T. J. Org. Chem. 2004, 69, 2595.

24) Kinoshita, H.; Shinokubo, H.; Oshima, K. Org. Lett. 2004, 6, 4085.

25) (a) Piechaczyk, O.; Doux, M.; Ricard, L.; Le Floch, P. Organometallics 2005, 24, 124. (b) Thoumazet, C.; Grützmacher, H.; Deschamps, B.; Ricard, L.; le Floch, P. Eur. J. Inorg. Chem. 2006, 3911. (c) Piechaczyk, O.; Thoumazet, C.; Jean, Y.; Le Floch, P. J. Am. Chem. Soc. 2006, 128, 14306. (d) Mora, G.; Deschamps, B.; van Zutphen, S.; Le Goff, X. F.; Ricard, L.; Le Floch, P. Organometallics 2007, 26, 1846

26) Usui, I.; Schmidt, S.; Keller, M.; Breit, B. Org. Lett. 2008, 10, 1207.

27) Pedley, J. B.; Marshall, E. M. J. Phys. Chem. Ref. Data 1983, 12, 967.

28) For reviews on the influence of the bite-angle of bidentate phosphane ligands, see: (a) van Haaren, R. J.; Oevering, H.; Coussens, B. B.; van Strijdonck, G. P. F.; Reek, J. N. H.; Kamer, P. C. J.; van Leeuwen, P. W. N. M. Eur. J. Inorg. Chem. 1999, 1237. (b) Oestreich, M. Eur. J. Org. Chem. 2005, 783. For a recent example, see: (c) Johns, A. M.; Utsunomiya, M.; Incarvito, C. D.; Hartwig, J. F. J. Am. Chem. Soc. 2006, 128, 1828.

29) (a) Dube, G.; Selent, D.; Taube, R. Z. Chem. 1985, 25, 154. (b) Kranenburg, M.; van der Burgt, Y. E. M.; Kamer, P. C. J.; van Leeuwen, P. W. N. M. Organometallics 1995, 14, 3081.

30) For a review, see: (a) Kamer, P. C. J.; van Leeuwen, P. W. N. M.; Reek, J. N. H. Acc. Chem. Res. 2001, 34, 895. For initial studies, see: ref. 32b and (b) Hillebrand, S.; Bruckmann, J.; Krüger, C.; Haenel, M. W. Tetrahedron Lett. 1995, 36, 75.

31) $\mathrm{Pt}$-catalyzed direct amination of allylic alcohols with ammonia to provide a mixture of mono-, $\mathrm{di}^{-}$, and triallylation products were reported, see: Ishimura, Y.; Nagato, N. Jpn. Kokai Tokkyo Koho JP 63002958, 1988 .

32) (a) Becke, A. D. J. Chem. Phys. 1993, 98, 5648. (b) Lee, C.; Yang, W.; Parr, R. G. Phys. Rev. B 1988, 37, 785.

33) For a review of self-assembling ligand, see: (a) Breit, B. Angew. Chem. Int. Ed. 2005, 44, 6816. For catalyses using 6-DPPon, see: (b) Breit, B.; Seiche, W. J. Am. Chem. Soc. 2003, 125, 6608. (c) Chevallier, F.; Breit, B. Angew. Chem. Int. Ed. 2006, 45, 1599. (d) Weis, M.; Waloch, C.; Seiche, W.; Breit, B. Angew. Chem. Int. Ed. 2007, 46, 3037. (e) Smejkal, T.; Breit, B. Organometallics 2007, 26, 2461.

34) For a review, see: (a) Trost, B. M.; Machacek, M. R.; Aponick, A. Acc. Chem. Res. 2006, 39, 747. For an initial study, see: (b) Trost, B. M.; Van Vranken, D. L. Angew. Chem., Int. Ed. Engl. 1992, 31, 228.

35) (a) Sacconi, L.; Gelsomini, J. Znorg. Chem. 1968, 7, 291. (b) Greene, P. T.; Sacconi, L. J. Chem. Soc. A 1970, 866. (c) Dapporto, P.; Sacconi, L. J. Am. Chem. Soc. 1970, 92, 4133. (d) Dapporto, P.; Sacconi, L. J. Chem. Soc. A 1971, 1914. (e) Thewissen, D. H. M. W.; Timmer, K.; Noltes, J. G.; Marsman, J. W.; Laine, R. M. Inorg. Chim. Acta 1985, 97, 143.

36) Mispelaere-Canivet, C.; Spindler, J.-F.; Perrio, S.; Beslin, P. Tetrahedron 2005, 61, 5253.

37) Mora, G.; Piechaczyk, O.; Houdard, R.; Mézailles, N.; Le Goff, X.-F.; le Floch, P. Chem. Eur. J. 2008, 14, 10047.

38) Lesueur, W.; Solari, E.; Floriani, C.; Chiesi-Villa, A.; Rizzoli, C. Inorg. Chem. 1997, 36, 3354.

39) (a) Stephenson, T. A.; Morehouse, S. M.; Powell, A. R.; Hefer, J. P.; Wilkinson, G. J. Chem. Soc., Chem. Commun. 1965, 3632. (b) Carrondo, M. A. A. F. de C. T.; Skapski, A. C. J. Chem. Soc., Chem. Commun. 1976, 410. (c) Carrondo, M. A. A. F. de C. T.; Skapski, A. C. Acta Crystallogr., Sect. B: Struct. Crystallogr. Cryst. Chem. 1978, B34, 1857. (d) Carrondo, M. A. A. F. deC. T.; Skapski, A. C. Acta Crystallogr., Sect. B: Struct. Crystallogr. Cryst. Chem. 1978, B34, 3576.

40) (a) Yamaguchi, T.; Sasaki, Y.; Nagasawa, A.; Ito, T.; Koga, N.; Morokuma, K. Inorg. Chem. 1989, 28, 4311. (b) Yamaguchi, T.; Sasaki, Y.; Ito, T. J. Am. Chem. Soc. 1990, 112, 4038. (c) Yamaguchi, T.; Ueno, T.; Ito, T. Inorg. Chem. 1993, 32, 4996. (d) Yamaguchi, T.; Abe, K.; Ito, T. Inorg. Chem. 1994, 33, 2689. (e) Yamaguchi, T.;
Shibata, A.; Ito, T. J. Chem. Soc., Dalton Trans. 1996, 4031. (f) Shibata, A.; Yamaguchi, T.; Ito, T. Inorg. Chim. Acta 1997, 256, 179. (g) Yamaguchi, T.; Saito, H.; Maki, T.; Ito, T. J. Am. Chem. Soc. 1999, 121, 10738. (h) Yamaguchi, T.; Shibata, A.; Ito, T. Chem.-Eur. J. 2001, 7, 5409.

41) (a) Ohashi, M.; Yagyu, A.; Yamagata, T.; Mashima, K. Chem. Commun. 2007, 3103. (b) Tanaka, S.; Yagyu, A.; Kikugawa, M.; Ohashi, M.; Yamagata, T.; Mashima, K. Chem.-Eur. J. 2011, 17, 3693. (c) Shinji, T.; Kazushi, M. Inorg. Chem. 2011, 50, 11384.

42) Unpublished results.

43) Recently, Pd-Xantphos/proline catalyzed $\alpha$-allylation reaction of enolizable ketones and aldehydes with allylic alcohols was reported, see: Usui, I.; Schmidt, S.; Breit, B. Org. Lett. 2009, 11, 1453.

44) For recent reviews, see: (a) Kappe, C. O. Angew. Chem. Int. Ed. 2004, 43, 6250. (b) Hayes, B. L. Aldrichim. Acta 2004, 37, 66. (c) Roberts, B. A.; Strauss, C. R. Acc. Chem. Res. 2005, 38, 653. For a recent study on nonthermal microwave effects, see: Herrero, M. A.; Kremsner, J. M.; Kappe, C. O. J. Org. Chem. 2008, 73, 36.

45) Although the reaction temperature was monitored using a standard IR temperature monitoring system and controlled by microwave irradiation power (standard mode) with an airflow cooling system (20 psi), IR temperature sensors in microwave reactors are not highly reliable for monitoring the reaction temperature because they only record the outer surface temperature of the reaction vessel and not the internal reaction temperature. Thus, the reaction temperature was also checked with an alcohol thermometer immediately after turning off the irradiation, revealing that the error in the IR temperature monitoring system was within $5{ }^{\circ} \mathrm{C}$. Later, we confirmed this finding using fiber-optic temperature probes. These results indicate that microwave irradiation has beneficial effects despite the fact that a number of recent studies reported that nonthermal microwave effects in organic chemistry do not exist. ${ }^{44}$

46) Shimizu, Y.; Morimoto, H.; Zhang, M.; Ohshima, T. Angew. Chem. Int. Ed. 2012, 51, 8654

47) (a) Appl, M. in Ammonia: Principles and Industrial practice, WileyVCH, Weinheim, 1999. (b) Appl, M. in Ammonia: Ullmann's Encyclopedia of Industrial Chemistry, 7th Ed, Wiley-VCH, New York, 2010.

48) For reviews, see: (a) Roundhill, D. M. Chem. Rev. 1992, 92, 1. (b) Lawrence, S. A. in Amines: Synthesis Properties, and Application, Cambridge University Press, Cambridge, 2004. (c) Willis, M. C. Angew. Chem. Int. Ed. 2007, 46, 3402. (d) Vlugt, J. I. van der Chem. Soc. Rev. 2010, 39, 2302. (e) Klinkenberg, J.; Hartwig, J. F. Angew. Chem. Int. Ed. 2011, 50, 86.

49) Nagano, T.; Kobayashi. S. J. Am. Chem. Soc. 2009, 131, 4200.

50) (a) Pouy, M. J.; Leitner, A.; Weix, D. J.; Ueno, S.; Hartwig, J. F. Org Lett. 2007, 9, 3949. (b) Pouy, M. J.; Stanley, L. M.; Hartwig, J. F. J. Am. Chem. Soc. 2009, 131, 11312.

51) (a) Defieber, C.; Ariger, M. A.; Moriel, P.; Carreira, E. M. Angew. Chem. Int. Ed. 2007, 46, 3139. (b) Roggen, M.; Carreira, E. M. J. Am. Chem. Soc. 2010, 132, 11917. 


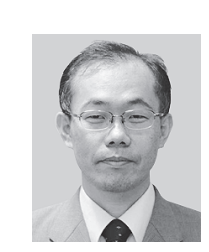

Takashi Ohshima is a Professor of Kyushu University. He was born in 1968 in Ehime, Japan. He received his bachelor's degree from The University of Tokyo in 1991 under the direction of Professor Masaji Ohno and received his $\mathrm{Ph} . \mathrm{D}$. degree from The University of Tokyo in 1996 under the direction of Professor Masakatsu Shibasaki. On the following year, he joined Otsuka Pharmaceutical Co., Ltd. for one year. After two years as a postdoctoral fellow at The Scripps Research Institute with Professor K. C. Nicolaou (1997-1999), he returned to Japan and joined Professor Shibasaki's group in The University of Tokyo as an assistant professor. He was appointed as Associate Professor of Osaka University in 2005. In 2010, he was promoted a full professor of Kyushu University. His research interests include development of highly atom-economical and environmentally benign catalytic process for the synthesis of biologically active compounds.

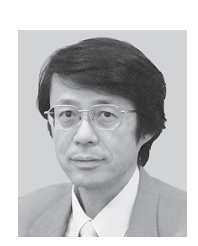

Kazushi Mashima received his Doctor degree (1986) from Osaka University. He became an Assistant Professor at Institute for Molecular Science, Okazaki National Institutes in 1983. He moved to Faculty of Engineering, Kyoto University as an Assistant Professor in 1989, and then to Faculty of Science, Osaka University in 1991. He was promoted to an Associate Professor at Faculty (now Graduate School) of Engineering Science, Osaka University in 1994, and then to a full Professor at Graduate School of Engineering Science, Osaka University in 2003. He worked with Professor M. A. Bennett, Australian National University in 1992 and Professor W. A.

Herrmann, Technisch Universität München in 1993. His current research interests lie in the area of organometallic and inorganic chemistry, emphasizing directions to asymmetric and polymerization catalysis as well as catalysis composed of polynuclear assembled metals. 